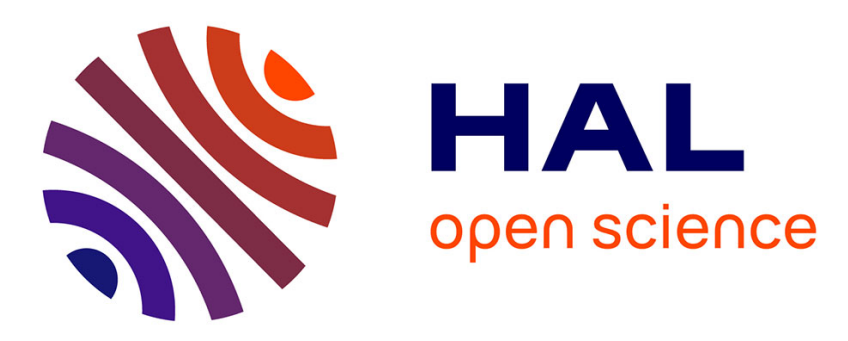

\title{
Flow patterns analysis using experimental PIV technique inside scraped surface heat exchanger in continuous flow condition
}

\author{
Mourad Yataghene, Francine Fayolle, Jack Legrand
}

\section{To cite this version:}

Mourad Yataghene, Francine Fayolle, Jack Legrand. Flow patterns analysis using experimental PIV technique inside scraped surface heat exchanger in continuous flow condition. Applied Thermal Engineering, 2011, 31 (14-15), pp.2855. 10.1016/j.applthermaleng.2011.05.011 . hal-00781361

\author{
HAL Id: hal-00781361 \\ https://hal.science/hal-00781361
}

Submitted on 26 Jan 2013

HAL is a multi-disciplinary open access archive for the deposit and dissemination of scientific research documents, whether they are published or not. The documents may come from teaching and research institutions in France or abroad, or from public or private research centers.
L'archive ouverte pluridisciplinaire HAL, est destinée au dépôt et à la diffusion de documents scientifiques de niveau recherche, publiés ou non, émanant des établissements d'enseignement et de recherche français ou étrangers, des laboratoires publics ou privés. 


\section{Accepted Manuscript}

Title: Flow patterns analysis using experimental PIV technique inside scraped surface heat exchanger in continuous flow condition

Authors: Mourad Yataghene, Francine Fayolle, Jack Legrand

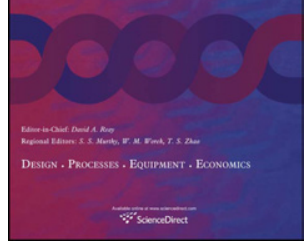

PII:

S1359-4311(11)00263-8

DOI:

10.1016/j.applthermaleng.2011.05.011

Reference: ATE 3558

To appear in: Applied Thermal Engineering

Received Date: 12 December 2010

Revised Date: 27 April 2011

Accepted Date: 8 May 2011

Please cite this article as: M. Yataghene, F. Fayolle, J. Legrand. Flow patterns analysis using experimental PIV technique inside scraped surface heat exchanger in continuous flow condition, Applied Thermal Engineering (2011), doi: 10.1016/j.applthermaleng.2011.05.011

This is a PDF file of an unedited manuscript that has been accepted for publication. As a service to our customers we are providing this early version of the manuscript. The manuscript will undergo copyediting, typesetting, and review of the resulting proof before it is published in its final form. Please note that during the production process errors may be discovered which could affect the content, and all legal disclaimers that apply to the journal pertain. 
4

5

6

7

8

9

10

11

12

13

14

15

16

17

18

19

20

21

22 8 9

Flow patterns analysis using experimental PIV technique inside scraped surface heat exchanger in continuous flow condition

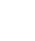

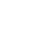

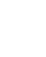

Mourad YATAGHENE ${ }^{1(*)}$, Francine FAYOLLE ${ }^{1}$, Jack LEGRAND ${ }^{2}$

8

(1)

(2)

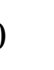

1

2

3

4

15

7

Correspondence should be sent to:

$1 *$ Dr. Mourad YATAGHENE

22 Email: yataghene@yahoo.fr 
1 Abstract

2

3 This study is focused on experimental analysis of the flow patterns inside scraped surface heat 4 exchanger (SSHE) under isothermal and continuous flow conditions. Experimental flow 5 pattern analyses are the basis for further experimental explorations of mixing and heat exchange mechanism. The 2D particle image velocimetry (PIV) is used to characterize the flow structure. Synchronization between the laser sheet and blades rotation was achieved in order to allow a statistical analysis of the obtained velocity vectors. Axial, radial and tangential velocity components have been examined. Newtonian and non-Newtonian shear thinning fluids are examined. The statistical results based on the calculation of the relative standard deviation show that the error made in the experiments is less than $2 \%$. The analysis of the axial velocity inside SSHE shows the presence of very large axial heterogeneities. At the entrance and exit of shearing region, axial velocity can reach 10 times the velocity corresponding to the imposed inlet mass-flow. These results illustrate the importance and extent of flow reversal for two used fluids and for $\mathrm{N}>4-5 \mathrm{rev} / \mathrm{s}$. Tangential velocity dominates around blades, and the maximum is reached near the tip of the blade. In most cases, the obtained velocities results near the walls shows a violating no-slip condition, which is due to the high velocity gradient near to the wall, and not captured by PIV. The radial velocity revealed a poor radial mixture near the rotor wall and the best mixing is localised on both sides of the blades. The results showed that under certain experimental flow conditions of rotating velocity and axial flow rate, a more effective flow can be obtained, which is characterised by low axial velocity dispersion. The obtained results in this work will be used to validate a $3 \mathrm{D}$ numerical model.

Key words: Mixing fluids, non-Newtonian, PIV flow measurement, fluid structure, scraped 35 surface heat exchanger. 


\begin{tabular}{|c|c|c|}
\hline \multicolumn{3}{|c|}{ Nomenclature } \\
\hline$d_{s}$ & stator diameter $(\mathrm{m})$ & normalized radial velocity $=u_{r} / \Omega \cdot R_{r}$ \\
\hline$d_{r}$ & rotor diameter $(\mathrm{m})$ & normalize tangential velocity $=u_{\theta} / \Omega \cdot R_{r}$ \\
\hline $\mathrm{D}_{\mathrm{p}}$ & mean diameter of seeded particles $(\mu \mathrm{m})$ & normalized axial velocity $=u_{z} / U_{d}$ \\
\hline i & coordinate in y-direction & volume of bowls (l) \\
\hline j & coordinate in $\mathrm{x}$-direction & total volume of SSHE (1) \\
\hline $\mathrm{k}$ & frame number in PIV measurements & axial velocity $(\mathrm{m} / \mathrm{s})$ \\
\hline K & consistency index $\left(\mathrm{Pa}_{\mathrm{s}} \mathrm{s}^{-\mathrm{n}}\right)$ & cartesian coordinate $(\mathrm{m})$ \\
\hline L & stator length (m) & \\
\hline N & impeller rotational speed (rev/s) & \\
\hline $\mathrm{n}$ & flow behaviour index & Greek letters \\
\hline$Q_{v}$ & volumetric flow rate $\left(\mathrm{m}^{3} / \mathrm{s}\right)$ & \\
\hline & radial position $(\mathrm{mm})$ & angular position $\left({ }^{\circ}\right)$ \\
\hline $\mathrm{r}^{*}$ & normalized radial position $=\left(r-R_{r}\right) /\left(R_{s}-R_{r}\right)$ & relative standard deviation \\
\hline $\mathrm{R}_{\mathrm{r}}$ & rotor radius & density $\left(\mathrm{kg} / \mathrm{m}^{3}\right)$ \\
\hline $\mathrm{R}_{\mathrm{s}}$ & stator radius $(\mathrm{m})$ & shear rate $\left(\mathrm{s}^{-1}\right)$ \\
\hline $\operatorname{Re}_{\text {axg }}$ & generalized Reynolds number & dynamic viscosity (Pa.s) \\
\hline & cross -section $\left(\mathrm{m}^{2}\right)=\pi\left(R_{s}^{2}-R_{r}^{2}\right)$ & frequency speed $\Omega=2 \pi \mathrm{N}\left(\mathrm{s}^{-1}\right)$ \\
\hline $\mathrm{T}$ & temperature $\left({ }^{\circ} \mathrm{C}\right)$ & \\
\hline & generalized Taylor number & \\
\hline $\mathrm{Ta}_{\mathrm{gc}}$ & critical Taylor number & \\
\hline $\mathrm{U}_{\mathrm{d}}$ & velocity based on axial flow rate " $Q_{v} / S "$ & \\
\hline $\mathrm{v}_{\mathrm{r},} \mathrm{v}_{\theta}$ & $\begin{array}{l}\text { velocity components in cylindrical coordinate } \\
(\mathrm{m} / \mathrm{s})\end{array}$ & \\
\hline
\end{tabular}




\section{1. Introduction}

2

3 Scraped surface heat exchangers (SSHE) are used in a wide variety of engineering applications such as the heat treatment of various viscous fluids. SSHE is used in chemical, pharmaceutical and food industries. The particularity of this device is to periodically scrape the surface heat exchange, which allows an improvement in the heat transfer and avoids the problems of the fluid fouling the exchange surface. Several studies have been carried out in order to examine the fluid flow pattern, especially in order to explain the non-uniformity of the temperature inside and at the exit of SSHE apparatus. The non-uniformity of the temperature field and the flow pattern are likely to be coupled, which is the main cause of deterioration of the heat exchanger efficiency. The flow in SSHE is the result of the superposition of a Poiseuille-type flow (axial flow) and a Couette-Taylor-type flow (rotational flow induced by the blades rotation). The presence of the scraping blades makes the fluid flow more complex and does not allow simple experimental measurements using temperature or velocity sensors, which are necessary for comprehension better understanding of the physical phenomena taking place in these devices. In the previous works given by others, two approaches were generally used to investigate the heat transfer and the fluid flow: experimental and numerical ones. In experimental approaches the authors first focused their studies on the determination of the residence time distribution (RTD) [1-4] which gives better information on the axial flow dispersion and eventually the global diagnostic of the presence of dead zones. The information obtained by RTD remains insufficient to describe the flow structure inside the SSHE. Velocity profiles using non intrusive methods such as (LDV, IRM and PIV) were carried out by Wang et al.[5,6] and Stranzinger et al.[7, 8] but only in a simplified geometrical configuration and in batch system (without axial flow rate). They conclude that the velocity profile in the annulus greatly depends on the behavior index of the shear thinning fluids. The flow regimes in SSHE can be identified by the Taylor number, and a critical Taylor number is used to characterize the passage from a laminar flow towards laminar vortical flow [9-12]. Dumont et al. [13] determined, using electrochemical technique, a limit value of the critical Taylor number $\mathrm{Ta}_{\mathrm{gc}}=60$ beyond which vortices appear, and another critical value of 80 when helical vortices start. The theoretical critical Taylor number is equal to 41.3 , the difference between the theoretical and SSHE value is explained by the presence of the blades, in fact the presence of the blades delays the onset of Taylor vortices.

Numerical investigations have also been made in order to investigate the heat transfer and the fluid flow in SSHE [14-18]. Numerical results show the existence of zones with recirculation 
1 upstream of the scraping blade [14]. According to the various studies carried out, the flow 2 pattern in a SSHE remains unknown. In order to give a better understanding of the flow 3 pattern in the SSHE, velocity measurements using Particle Image Velocimetry (PIV) were 4 done.

5 Although PIV had its genesis several years ago, its more common usage occurred in the last decade. Owing to the ability of $P I V$, in principle, to provide information about a flow field, simultaneously in different points, its use is sure to become even more widespread. PIV is an instantaneous whole-field measurement technique, which uses pulsed light laser to illuminate a fluid flow seeded with tracer particles. It can potentially provide more information about the flow mechanism than the conventional technique. The bibliography of Adrian [19] gives an indication of the historical development of PIV, while different PIV techniques are described in the studies made by Adrian [20] and Raffel et al. [21]. Several recent studies [22-24] have demonstrated the application of PIV to complex flows. An important aspect of PIV is its ability to measure the vorticity field and spatial correlations $[25,26]$. To some extent, PIV still suffers limitations in the dynamic range of velocity measurement, though significant improvements have been made [27]. Other limitations on the quality of data arise due to the size of seed particles, as well as image quality and size, camera frame rate, processing software, etc.

Despite a number of studies on SSHE hydrodynamics, there have been no studies reported in the open literature to use PIV in continuous flows conditions in order to obtain information about the flow fields in this type of equipment.

The originality of this work is to use the PIV technique to study the fluid flow inside SSHE under isothermal and real flow conditions. In order to understand the flow structure in more details, PIV technique flow measurement was used. The $(r, z)$ and $(r, \theta)$ velocities components were obtained for Newtonian and non Newtonian shear thinning fluids. The results could give the time evolution of the spatial distribution of the velocity. In order to reach these objectives, a series of velocity vectors graphs and profiles at different cross sections inside the SSHE are presented in the case of Newtonian and non-Newtonian shear thinning fluids for different $\mathrm{z}$ locations. 


\section{2. Experimental Setup and Approach}

\section{2.1. Experimental Devices}

4 The PIV technique is a non intrusive flow measurement. The principle of PIV is to illuminate seeded particles added into the fluid with laser sheet in a cross-section. The seeded fluid flow particles are captured by a CCD camera. To have access to the cross-sections inside the device, it was necessary to have transparent walls and fluids.

Fig.1 shows the schematic drawing of experimental system, the all dimensions of the pilot SSHE are given in Table 1.

10 The fluid is pumped through the inlet bowl via the volumetric pump with limits ranging from $5.510^{-6}$ to $5.510^{-5} \mathrm{~m}^{3} / \mathrm{s}$ and flows back to the storage tank, with volume capacity of 301 . An electromagnetic flowmeter (Promg 33 type) is placed at the exit of the exchanger, and gives the flow rate in $\mathrm{kg} / \mathrm{s}$. The rotating velocity of the rotor (thus of the blades) is regulated with an electronic variator with a range of speed of 1 to $10 \mathrm{rev} / \mathrm{s}$.

The particle image velocimetry (PIV) is used to provide instantaneous velocity field measurements in a longitudinal and vertical cross-section of the exchanger. A laser light flash sheet illuminates particles in the flow field and a digital camera captures the two points in time. The resulting flow velocity extracted from this couple of digital images is an instantaneous snapshot of the flow in the area viewed, in stationary conditions. The seeding (PSP, $50 \mu \mathrm{m}$ diameter, $1.03 \mathrm{~g} / \mathrm{cm}^{3}$ ) was adjusted to 5-10 particles per interrogation window. The PIV system used for the determination of the velocity fields is essentially composed of a CCD camera of 1600x1186 pixels resolution (Dantec Dynamics Flow, Sense M2/E 8 bit) with a Nikon objective $(60 \mathrm{~mm})$, a pulsed Nd-Yag $15 \mathrm{~mJ}$ laser (New Wave Solo). The PIV recordings from the camera are acquired with the PIV software package FlowManager from Dantec Technology. For these images, a cross-correlation analysis method is used with interrogation, window size of $64 \times 64$ pixels $^{2}$, which corresponds in the light-sheet to an area of approximately $0.8 \times 0.8 \mathrm{~mm}^{2}$ and an overlap of $50 \%$ on the final pass. For the two frames, cross-correlation and fast Fourier methods are applied in the data processing. For each measurement, 100 image pairs are used and the statistical average vector is calculated in order to obtain the time averaged for this flow field. In order to eliminate optical distortion caused by the curved external surface of the SSHE (cylindrical geometry), a full parallelepiped Plexiglas was dug with the cylindrical tube representing the exchanger stator (Fig.2). The presence of the blades in the annulus requires the installation of a synchronization system. The main objective is to always obtain the same position of the blade for any laser impulsion, 
1 thereby allowing one to apply statistical calculations on the obtained velocity vectors. The

2 synchronization is ensured by a photodiode which delivers a signal for every scraper blade

3 revolution towards the laser controller. The image synchronization was based on the

4 assumption that the scraper blade keeps a constant rotational speed.

5 PIV measurements are carried out under the conditions gathered in Table 2.

6 These operating conditions are selected in order to cover flow conditions and to know the

7 influence of each of these parameters such as the flow rate and the rotating velocity on the

8 velocity profiles. They also are selected according to the flow conditions used in food

9 industries. The dimensionless numbers (Reynolds and Taylor numbers) presented in Table 2

10 are generally used to characterize fluid flow regime in SSHE. According to Table 2, we notice

11 that the flow regime in all considered operating conditions is laminar. In addition, for a Taylor

12 number superior to 60 it is possible to have secondary flows, called Taylor vortices [12].

\subsection{Working Fluids}

In this study, two fluids were examined, a Newtonian and a non-Newtonian shear thinning.

The study aims to examine the flow pattern of liquid food products; the two selected fluids must be close to those treated in scraped surface heat exchangers. Glycerin has a high viscosity $\left(1.31 \mathrm{~Pa} . \mathrm{s}\right.$ at $\left.18^{\circ} \mathrm{C}\right)$ and $1 \% \mathrm{CMC}$ solution was a non-Newtonian shear thinning fluid, with rheological behavior similar to yoghourt. The rheological behavior of the working fluids is measured by using a standard rheometer (AR1000) with Couette geometry under the shear rate between 1-2500 1/s and at constant temperature of $18^{\circ} \mathrm{C}$. The non-Newtonian fluid used was an aqueous CMC solution (Carboxyl-Methyl-Cellulose), which was a shear thinning fluid and was not perfectly transparent like glycerin. The use of a not perfectly transparent fluid did not prevent its use, but there was a limit depth beyond which the CCD camera of PIV could not capture the particles displacement of the illuminated laser plane (for 1\% CMC this limit depth was about $15 \mathrm{~cm}$ against $40 \mathrm{~cm}$ for glycerin); this depth limit concerns $(\mathrm{r}, \theta)$ planes. The density of the fluids was measured with a densitometer. Table 3 gives the results of the rheological and density measurements data for fluids used. In the experiment and in order to make sure that the working fluid was not degraded by the action of the blade (shearing effect) or by any other experimental factor (dilution, light,...etc) the measurements of viscosity and density were systematically checked after each experiment test. If the fluid presented a change in viscosity, it was replaced by another preparation for further experimentation. In general no high fluid degradation was observed. 


\section{$1 \quad$ 2.3. Statistical velocity fields analysis}

2

3 The collected instantaneous velocity vector maps taken from a regular grid of points are 4 obtained after a correlation processing the particle image data. For each test cross-section, 100 5 frames of transient velocity field were obtained in the experiment. The time averaged velocity

6 field of each cross section test was then obtained through continuous processing. The average

7 time value of the velocity components is given by:

$8 \quad \bar{u}_{i, j}=\frac{\sum_{k=1}^{100} u_{i, j, k}}{100}$

$9 \bar{v}_{i, j}=\frac{\sum_{k=1}^{100} v_{i, j, k}}{100}$

10 Where $u_{i, j, k}$ is the velocity component in the $x$-direction of the measured point $(i, j)$ in the

11 frame $\mathrm{k}$ and $\mathrm{v}_{\mathrm{i}, \mathrm{j}, \mathrm{k}}$ is the $\mathrm{y}$-direction velocity component of measured point $(\mathrm{i}, \mathrm{j})$ in the frame $\mathrm{k}$.

12 The standard deviation value of velocity components is then defined as:

$13 \Delta u_{i, j}=\sqrt{\frac{\sum_{k=1}^{100}\left(u_{i, j, k}-\bar{u}_{i, j}\right)^{2}}{99}}$

$14 \Delta v_{i, j}=\sqrt{\frac{\sum_{k=1}^{100}\left(v_{i, j, k}-\bar{v}_{i, j}\right)^{2}}{99}}$

15

$20 \quad \delta=\frac{\sqrt{\Delta u_{i, j}^{2}+\Delta v_{i, j}^{2}}}{\sqrt{\bar{u}_{i, j}^{2}+\bar{v}_{i, j}^{2}}}$

21 The use of the relative standard deviation will enable us to combine measurements errors 22 from different sources. When the flow regime is turbulent, $\delta$ represents the turbulence 23 intensity. In this study and under all considered operating conditions, the flow regime remains 24 laminar. The relative standard deviation here represents the uncertainty of the flow 25 measurements. 


\section{1}

2

3 The pulsed laser light sheet is not able to illuminate the whole test section, because the 4 physical dimension of the pilot system is large. The area of the measured velocity field 5 captured by the CCD camera is limited to $90 \times 80 \mathrm{~mm}^{2}$. Due to this limitation and in order to 6 7

\subsection{The selection of test sections}

(1)
cover the whole geometry of the exchanger according to z-direction, three laser planes were considered (Fig.3). Hence, in this configuration, axial and radial velocities can be determined in the whole system. For the measurement of the radial and tangential velocities the CCD camera cannot capture the image further than $13 \mathrm{~cm}$ deep due to the poor transparency of the working fluids in the case of $1 \%$ CMC solution. In the case of glycerin, five (05) laser sheet planes are examined corresponding to normalized $z^{*}$ - locations of $0.2,0.3,0.6,0.9$ and 0.97 (Fig.3),. To obtain all these planes, two transparent bowls are used: one at the entrance and the second at the exit of the exchanger, thereby allowing the view of all presented planes.

Fig.2 shows the diagram of the laser and camera positions allowing us to obtain three velocity components. Fig. 3 shows the different positions of the measured planes in both directions. By using only one CCD camera for the PIV acquisition, it is not possible to obtain the three velocity components in space at the same time, but it enables us to measure two velocity components at the same time. To obtain three velocity components $\left(\mathrm{v}_{\mathrm{z}}, \mathrm{v}_{\mathrm{r}}, \mathrm{v}_{\theta}\right)$, two series of measurements were required.

The results obtained by PIV are expressed in a Cartesian plane. In order to represent the velocity components in the $(r, \theta)$ plane, a transformation is needed to pass towards polar coordinates. If $\mathrm{v}_{\mathrm{x}}$ and $\mathrm{v}_{\mathrm{y}}$ are the Cartesian velocity components in the reference plane of $(\mathrm{x}, \mathrm{y})$ and $v_{r}, v_{\theta}$ are the polar velocity components in the reference of $(r, \theta)$, the transformation is given by:

$u_{r}=u_{x} \cos \theta+u_{y} \sin \theta$

$u_{\theta}=u_{x} \sin \theta-u_{y} \cos \theta$

where $\theta$ is angular position.

The calculation of the mean velocity, standard deviation and all presented results were made using the computing language Matlab $^{\mathrm{TM}}$.

\section{Results and discussion}

This study was focused on exploring experimental results obtained by PIV technique, in real flow condition of a rotating machine of SSHE. In this section, a statistical analysis of the 
1 obtained velocity vectors is first presented and analyzed. Secondly, when the obtained results

2 are reliable, analyses of the obtained velocities vectors are given, and the flow structure in

3 SSHE is discussed.

4

5

6

7

\subsection{Statistical analysis results}

In a typical PIV experiment, several double-frame images are captured and processed in order to calculate instantaneous velocity fields. These data are directly applicable for the computation time-mean statistics, such as mean and rms (root mean square) fields and several derived quantities such as vorticity, shear rate and streamlines. The 2D-PIV data can also be used to compose a $3 \mathrm{D}$ volume for the time-mean statistics by combining several individual measurement planes. A visual examination of PIV data allows observation of the spatial scales and the nature of coherent flow structures. However, a careful analysis of these features is sometimes needed. A statistical analysis of the obtained vectors makes it possible to know the average error made for the velocity measurement using the PIV. Calculation results are presented here for working fluids mentioned in Table 2 and specifically in the case of $\mathrm{N}=3$ rev/s with an axial mass flow rate of $1.3810^{-5} \mathrm{~m}^{3} / \mathrm{s}$. Fig.4 shows an example of the distribution of the relative standard deviation $(\delta)$ using equation (5) for the middle r-z plane of the SSHE. Fig. 4 shows that the relative standard deviation is less than $0.5 \%$ for the four considered fluids, which is an acceptable error. Globally, the relative standard deviation in $(\mathrm{r}, \theta)$ and $(\mathrm{r}, \mathrm{z})$ cross-sections planes of the time average velocity is less than $2 \%$ for all experiments. An example of the same calculation of the relative standard deviation for $(\mathrm{r}-\theta)$ plane corresponding to the $\mathrm{z}$ location of $\mathrm{z}^{*}=0.2$ is given in Fig.5. It can be noted that in the case of $(\mathrm{r}-\theta)$ plane the errors are mainly located in the zone of an existing shadow area created by the blade. According to this statistical analysis, we deduced that the error of measurement made by using PIV is not significant and that the results can be reliable. The presence of the shadowed zone locally increases locally the relative standard deviation, which can reach a maximum of $4.5 \%$ for $1 \%$ CMC solution and $2.5 \%$ of pure glycerin. Therefore, in this study, we only present the velocity vectors corresponding to the half plane located between the angular position of $0<\theta<180^{\circ}$ which corresponds to the relative standard deviation which is less than $2 \%$. 


\subsection{Tangential velocity inside SSHE}

2

3 Fig.6 shows the obtained result of the contours velocity magnitude of $\sqrt{v_{\theta}^{2}+v_{r}^{2}}$ in the case of pure glycerin. Before the fluid flowed to the sheared part $\left(\mathrm{z}^{*}=0.16\right)$, the flow had a similar behavior to that of a Couette-Taylor, with a maximum velocity on the rotor and zero velocity on the stator, with a linear velocity profile in the case of a Newtonian fluid. Once it was in the sheared zone $\mathrm{z}^{*}>0.16$ (presence of blades) the flow pattern completely changed. The comparison between all obtained velocity contours for each plane shows a perfect similarity of the flow configuration in the presence of the blades. There is an increase of the velocity behind (wake) and in front of the blade. The same observations were obtained with $1 \% \mathrm{CMC}$ solution. The influence of the axial flow rate does not add a visible change to the contours.

Studies about the flow across SSHE were mainly handled by Wang et al. [5, 6, 37, and 38]. They used two methods to determine the axial and tangential velocity components: an analytical method to solve continuity and momentum equations and an experimental method using MRI (Magnetic resonance Imaging). In their study, they used a simple geometry with only one blade. The results of these authors were obtained in annular space far away from the blades. A numerical study was also made by Stranzinger et al. [7, 39] and recently by Yataghene et al. [18] based on the solving of continuity and momentum equations by using a commercial software computation in 2D geometry. The results of the numerical computation showed that the blades greatly affected tangential velocity, but no experimental validations were available until now. The use of $2 \mathrm{D}$ numerical models does not allow the authors to examine the axial velocity. In order to supplement these studies already carried out, we suggest examining the tangential velocity profiles for different angular positions $(\theta)$. The results given by Wang et al. [37] showed that the flow rate did not significantly affect the tangential velocity profile, which was confirmed in this work. We examined in detail a plane corresponding to $\mathrm{z}^{*}=0.20$, where we can reasonably assume that the flow was mainly controlled by the blades. The plane corresponding to $z^{*}=0.20$ is located exactly at the entrance of the fluid in the sheared region with the presence of the blades (see. Fig.7). The synchronization system allowed the measurement of the velocity by respecting the same position of the blades for every passage. In the same manner, the tangential velocity normalized by $\left(2 \pi R_{r} N\right)$, where $R_{r}$ represents the rotor radius, was plotted.

An example of a seeded flow of the cross-section of $z^{*}=0.20$ is presented in Fig.7 (a), where the position of the two blades are visible. Fig. 7 (a) also shows that, behind the rotor, a 
1 shadowed zone was created by the blades laser reflexion. For this reason, only the velocity

2 profiles included between the angular position of 0 and $180^{\circ}$ are presented in Fig. 7 (b).

3 The results of the obtained normalized tangential velocity corresponding to the different 4 angular positions as shown in Fig 7 (b) are given in Fig.8 for the case of the pure glycerin and $51 \% \mathrm{CMC}$ solution under the flow conditions of $\mathrm{N}=3 \mathrm{rev} / \mathrm{s}$ and $Q_{v}=1.3810^{-5} \mathrm{~m}^{3} / \mathrm{s}$. The positions of $\theta=0^{\circ}$ and $\theta=180^{\circ}$ correspond to a slipstream behind the 1 st and the 2 nd blade, $\theta=150^{\circ}$ corresponds to the front of the scraping blade, and the other angular positions of $\theta=60^{\circ}, \theta=90^{\circ}$ and $\theta=120^{\circ}$ correspond to the annulus space. The position $r^{*}=0$ correspond to the rotor wall and $\mathrm{r}^{*}=1$ correspond to the stator wall.

The tangential velocity profiles were completely deformed in the presence of the blades, the maximum of the tangential velocity was obtained near the stator located at a distance from 3/4.r* which corresponds to $1.6 \times \Omega . R_{r}$.

In addition, it has been noted that the condition of no-slip is not respected on the stator wall in the case of the passage blade: the passage of the blade completely destroyed the hydrodynamic boundary layer developed on the wall of the stator (Fig.7 (b) for the different angular positions corresponding to $\theta=0^{\circ}, 150^{\circ}$ and $180^{\circ}$ ). It also appears in Fig.8 (a,b) that near the rotor wall velocity is not zero. This can be explained by the low accuracy of the PIV near the walls, and the rotation of the rotor effect. For the same angular $\theta$-positions of $\theta=0^{\circ}$, $150^{\circ}$ and $180^{\circ}$, the tangential velocity at the stator wall is not null; this is perhaps due to the blade entrainment at this wall, which remove the boundary layer. It is also highly probable that no-slip condition is verified but there is a high velocity gradient near to the wall which was not captured by the PIV.

\subsection{Axial and radial velocity inside SSHE}

The axial and radial velocity profiles under considered experimental conditions were studied. Two fluids were used, a Newtonian one of pure glycerin, and a 1\% CMC solution. Two axial flow rates conditions were examined. The selected axial flow rate was 0.017 and $0.051 \mathrm{~kg} / \mathrm{s}$ for glycerin, and 0.014 and $0.043 \mathrm{~kg} / \mathrm{s}$ for $1 \%$ CMC solution. Three rotating velocities of 1,3 and $5 \mathrm{rev} / \mathrm{s}$ were investigated. For all these operating conditions the flow remained laminar without Taylor vortices (i.e. Table 2), as already mentioned in the introduction. The most authors who are working on the SSHE compare usually the axial velocity with this of 
1 Couette- Poiseuille flow. The axial velocity profile in the case of Couette-Poiseuille is given 2 by $\frac{v}{v_{0}}=\frac{3_{n+1}}{n+1}\left(1-\left(\frac{r}{R}\right)^{\frac{n+1}{n}}\right)$, where $\mathrm{n}$ represents the flow index behavior of the power law 3 fluid. In the case of a Newtonian fluid $(n=1)$ the profile was strictly parabolic, and when $0<n$ $4<1$ the profile became increasingly plate with decreasing of the index flow behavior $n$. In the 5 classical case of Couette-Poiseuille flow the axial velocity profile is parabolic for Newtonian 6 fluid, with the maximum axial velocity equal to twice the mean velocity corresponding to the 7 imposed axial flow rate [6, 31]. Wereley and Lueptow [32] have shown that even for a Taylor vortices flow regime, the averaged velocity profiles were remarkably similar to the stable theoretical parabolic velocity profile. These results clearly indicate that, in the case of Couette-Poiseuille flow, the vortical flow regime has only a very small effect on the axial velocity profile and that the effect is largely independent of the characteristics of the vortical flow [32]. This result is particularly interesting when the effect of the Taylor vortices occurs. Fig.9 (a,b) shows an example of the velocity vectors projection on the (r,z) plane, in the case of the axial flow rate of $1.3810^{-5} \mathrm{~m}^{3} / \mathrm{s}$ and for rotating velocity of $\mathrm{N}=5 \mathrm{rev} / \mathrm{s}$, in the entrance and the exit planes of the exchanger. The experimental investigation on the flow structures conducted by Härröd [9] in SSHE has shown helical behavior. The same flow pattern as the one observed by Härröd [9] was obtained in the middle of the exchanger, and far from the entrance and exit SSHE-planes, where the flow presents an important change of the axial velocity in the $\mathrm{z}$ ranged between $70<\mathrm{z}(\mathrm{mm})<110\left(0.16<\mathrm{z}^{*}<0.25\right)$. The reversed flow was also observed under certain flow conditions of axial flow rate, rotating velocity and type of fluids. For glycerin solution, the reversed flow was especially important in the region defined by: $410<z(\mathrm{~mm})<440\left(0.93<\mathrm{z}^{*}<1\right)$, as showed in Fig.9 (a,b).

According to the observations obtained in this work, the flow structure or the general tendency of the flow pattern in the r-z plane remains helical, except at the entrance and exit plane, where the axial velocity is highly influenced by the rotating velocity and imposed axial flow rate. After analyzing the different velocity vectors results, it should be noted that for a higher rotating velocity $(\mathrm{N}>5 \mathrm{rev} / \mathrm{s})$ and under a low axial flow $\left(<1.3810^{-5} \mathrm{~m}^{3} / \mathrm{s}\right)$, there is a reverse flow at the exit of SSHE.

To quantify this flow tendency, axial velocity profiles were plotted in Figs. $10 \& 11$ for various $\mathrm{z}^{*}$-locations of $0.2,0.3,0.6,0.9$ and 0.97 , and for $\theta=90^{\circ}$ under all considered operating conditions. These $\mathrm{z}^{*}$ locations correspond to the limits between the entrance and exit of the fluid in the sheared zone (presence of the blades) respectively. The other working 
1 fluids (0.5\% CMC solution or $15 \%$ water glycerin) are not presented here, but results are

2 commented. Fig.10 shows the results of the normalized average axial velocity $\left(v_{\mathrm{z}}{ }^{*}\right)$ profiles

3 with dimensionless radial position ( $\mathrm{r}^{*}$ ) of pure glycerin.

4 To demonstrate the existence of the reverse flow at the exchanger exit, a criterion based on

5 the axial and radial velocity components should be defined. For example, in the case of the

6 glycerin fluid, and for $\mathrm{v}_{\mathrm{z}}{ }^{*}\left(\mathrm{z}^{*}=1, \theta=90^{\circ}, \mathrm{r}^{*}=0.25\right)$ and $\mathrm{u}_{\mathrm{r}}{ }^{*}\left(\mathrm{z}^{*}=0.9, \theta=90^{\circ}, \mathrm{r}^{*}=0.25\right)$ and except

7 for $1 \mathrm{rev} / \mathrm{s}$, the negative sign observed on the velocity given in Figs. $10 \& 11$ reflects the reverse flow character in the axial flow direction. In the great majority of the obtained axial velocities profiles, it can be seen for the low rotating shaft velocity $(\mathrm{N}=1 \mathrm{rev} / \mathrm{s})$, that the profiles are almost parabolic with a maximum ranged between 2 and 2.5. Important changes on the axial velocity are observed with increasing the blade rotation.

Due to the significant differences of obtained results between the glycerin and $1 \% \mathrm{CMC}$ solution, it is difficult to discuss both fluids at the same time. Hereafter, we will first discuss first the results of the glycerin and then $1 \% \mathrm{CMC}$ solution.

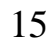

According to the obtained results, four observations can be given:

- The axial velocity $v_{\mathrm{z}}^{*}$ is highly influenced (Fig. 10) by the rotating velocity: $v_{z}{ }^{*}\left(z^{*}=0.19, \theta=90^{\circ}, r^{*}=0.5, N=5 \mathrm{rev} / \mathrm{s}, Q_{v}=1.3810^{-5} \mathrm{~m}^{3} / \mathrm{s}\right)=11.8$. The maximum axial velocity measured is about 10 times higher than the velocity of imposed axial flow rate at inlet plane. The increase of the rotational speed promotes axial velocity heterogeneity at the entrance of the exchanger, for example: $N=5 \mathrm{rev} / \mathrm{s}_{2} v_{z}^{*}\left(z^{*}=0.19\right.$, $\left.\theta=90^{\circ}, r^{*}=0.5, Q_{v}=1.3810^{-5} \mathrm{~m}^{3} / \mathrm{s}\right)=11.8$ and $N=3 \mathrm{rev} / \mathrm{s}, v_{z}{ }^{*} z^{*}=0.19, \theta=90^{\circ}, r^{*}=0.5$, $\left.Q_{v}=1.3810^{-5} \mathrm{~m}^{3} / \mathrm{s}\right)=6.2$.

- The increase of the rotating velocity facilitates the appearance of a preferential way of the fluid near to the rotor. The channelling phenomena can be explained by the action of the axial pressure induced by the rotating speed of the rotor.

- For $\mathrm{N}=5 \mathrm{rev} / \mathrm{s}$ reverse flow at the exit is important, it can reach almost 10 times the velocity of the imposed axial flow rate: $v_{z}{ }^{*}\left(z^{*}=1, \theta=90^{\circ}, r^{*}=0.25, Q_{v}=1.3810^{-5} \mathrm{~m}^{3} / \mathrm{s}\right.$, $N=5 \mathrm{rev} / \mathrm{s}) \cong-10$ (Figs. 10\&11). 
- The increase in the axial flow rate tends to stabilize the axial flow heterogeneity in SSHE, especially at the entrance and exit of the heat exchanger. For example, according to data given in Fig.11: $v_{z}{ }^{*}\left(z^{*}=0.97, \theta=90^{\circ}, r^{*}=0.25, Q_{v}=1.3810^{-5} \mathrm{~m}^{3} / \mathrm{s}\right.$, $N=5 \mathrm{rev} / \mathrm{s}) \cong 12$ and $v_{z}{ }^{*}\left(z^{*}=0.97, \theta=90^{\circ}, r^{*}=0.25, Q_{v}=4.210^{-5} \mathrm{~m}^{3} / \mathrm{s}, \mathrm{N}=5 \mathrm{rev} / \mathrm{s}\right) \cong 5$. At the exit plane of the exchanger, the influence of the axial flow rate plays an important role to considerably reduce the reverse flow: $v_{z}{ }^{*}\left(z^{*}=0.97, \theta=90^{\circ}, r^{*}=0.25\right.$, $\left.Q_{v}=1.3810^{-5} \mathrm{~m}^{3} / \mathrm{s}, N=5 \mathrm{rev} / \mathrm{s}\right) \cong-10$ against $v_{z}{ }^{*} z^{*}=0.97, \theta=90^{\circ}, r^{*}=0.25, Q_{v}=4.210^{-5}$ $\left.\mathrm{m}^{3} / \mathrm{s}, \mathrm{N}=5 \mathrm{rev} / \mathrm{s}\right) \cong-1$.

Fig.11 (a,b) shows the normalized axial velocity component under considered operating flow conditions, in the case of non-Newtonian shear thinning solution of $1 \%$ CMC.

The velocity profile shows the complexity of the fluid flow. The acceleration previously observed in the case of glycerin was also obtained for $1 \% \mathrm{CMC}$ solution, with a maximum velocity 12 times greater than the mean velocity. At the exit of the exchanger, no important reverse flow was obtained. For $z^{*}=0.3$, a major change in the axial velocity profiles was observed in the case of $N=3 \& 5 \mathrm{rev} / \mathrm{s}$. For example, the axial velocity profiles of $v_{z}^{*}\left(z^{*}=0.3\right.$, $\theta=90^{\circ}, \mathrm{r}^{*}, Q_{v}=4.210^{-5} \mathrm{~m}^{3} / \mathrm{s}, Q_{v}=1.3810^{-5} \mathrm{~m}^{3} / \mathrm{s}, N=3 \mathrm{rev} / \mathrm{s}, N=5 \mathrm{rev} / \mathrm{s}$ ) present (Fig. 11) important deformations.

The flow complexity can be explained by the shear rate depending fluid. The axial velocity profiles were not parabolic like pure glycerin, and were much more influenced by rotating velocity.

So far, the experimental analysis of the radial velocity in a SSHE has never been handled. This study allows us to know the effectiveness of the radial mixing in the SSHE. With $r-z$ planes, we can access to single radial velocity profile, but at different z-locations, and for $(r, \theta)$ planes it was possible to have flow visualisation of cross-section inside SSHE. Note that the radial velocity profiles obtained by the two planes $(r, z)$ and $(r, \theta)$ were similar.

Fig. $12(a, b)$ shows the radial velocity profiles normalized by $\left(2 \pi R_{r} N\right)$ in each considered $(r, z)$ plane corresponding to $z^{*}$-locations of $0.2,0.3,0.6$ and 0.97 , which represent the entry, the middle and the exit of the sheared zone respectively. Three rotating velocities are compared $\left(N=1,3\right.$ and $5 \mathrm{rev} / \mathrm{s}$, with a flow rate of $\left.Q_{v}=4.210^{-5} \mathrm{~m}^{3} / \mathrm{s}\right)$. For Newtonian fluid, the radial velocity profiles for all the considered conditions show an identical general shape (Fig. 12). For the exit plane the presence of the reverse flow has an influence on the radial 
1 velocity which is visible on Fig.12. In the case of $1 \% \mathrm{CMC}$ solution, the general layout of the

2 obtained radial velocity strongly depends on the operating conditions (such as rotating 3 velocity and axial flow rate). This dependence can be explained by the non Newtonian behaviour of the fluid which is influenced by the shearing generated in the fluid. At the exit of the exchanger with $z^{*}$-location ranging between $0.77<z^{*<1}$ and in the case of the two considered fluids, the radial mixture is poor and corresponds to $5 \%$ of $2 \pi R_{r} N$. The reverse flow phenomenon at the exit plane is not observed for $1 \% \mathrm{CMC}$ solution under a rotating velocity of $\mathrm{N}=1 \mathrm{rev} / \mathrm{s}$. The radial velocity in the case of $1 \% \mathrm{CMC}$ solution is more significant than in the case of pure glycerin, which can reach for a velocity of $N=5 \mathrm{rev} / \mathrm{s} 40 \%$ of $\left(2 \pi R_{r} N\right)$ against $15 \%\left(2 \pi R_{r} N\right)$ for pure glycerin. It is noted that the increase in the rotating velocity in the case of $1 \% \mathrm{CMC}$ solution increases the effectiveness of the radial mixture, but also the presence of a preferential way close to the rotor. In the case of flow rate of $Q_{v}=1.38$ $10^{-5} \mathrm{~m}^{3} / \mathrm{s}$ and under the same operating conditions as previously, it is shown that the lower the flow rate, the better radial mixture.

In addition, Fig.13 (a,b) gives the radial velocity profiles for the two considered operating flow conditions. It can be seen that the velocity curves greatly depend on the blades position, and near the blades the radial velocity becomes more important. The profile near the blade is parabolic, and far from the blade the radial velocity is almost zero.

Fig.14 shows an example of radial velocity distribution in the cross-section located at $\mathrm{z}^{*}=0.6$. For all examined operating conditions and fluid type, a similar radial velocity distribution is obtained. The most important radial mixing is located around the blades. The blades periodically scrape the fluid contained in the handled sheared volume, and a layer without mixing is present near the rotor (Fig.14). Outside the blades zones the radial velocity remains almost null, which leads to very poor radial mixing.

\section{Conclusions}

As flow patterns are important in understanding the mixing and heat transfer mechanisms in the scraped surface heat exchanger, the experimental PIV technique was used to measure different velocities components; such as radial, tangential, and axial ones in real flow conditions. In the food industries that use the SSHE, the main fluids are non Newtonian shear thinning, e.g. yoghurt, cheese melt, mayonnaise, etc. This study is the first one that analyses three velocities components $\left(v_{r}, v_{\theta}, v_{z}\right)$ on different cross-sections inside the SSHE. One 
1 reason for this lack of data is the complexity of the experimental configuration - several

2 arrangements had to be made, such as the synchronisation system which is needed to obtain 3 the average velocity. A statistical analysis was carried out to see the degree of confidence of the obtained PIV results. The statistical parameter which allowed us to identify errors of measurement was the standard deviation, and it proved that the presence of the shadowed zones created by the blades made the particles less visible with the camera, which gives erroneous vectors. Therefore, these zones were excluded from the study. The study of axial velocity under large operating conditions showed strong axial velocity heterogeneities, for $\mathrm{N}>4-5 \mathrm{rev} / \mathrm{s}$ and for a flow rate of $Q_{v}=1.3810^{-5} \mathrm{~m}^{3} / \mathrm{s}$, which can reach 10 times the velocity of the imposed flow rate. These conditions show the existence of a large axial dispersion. The increasing in the flow rate stabilizes the flow. Under the above operating conditions, there are very significant axial velocities close to the rotor, which allows assuming the presence of two layers of fluids that run out at two different speeds in simple shearing. The analysis of radial velocity gives information on the radial mixture. After the examination of the obtained vectors in the $(r, \theta)$ planes, it seems that the radial mixture is mainly imposed by the blades, and is more effective on both sides of the blades, and null in the remainder of the exchanger. The radial mixture is poor, which can generate significant differences on the quality of the heat treatments inside the SSHE. With regards to the tangential velocity components, the fluid contained in the presence of the blades is controlled by the tangential velocity; the maximum speeds can reach 1.6. $\mathrm{u}_{\theta(\text { (rotor) }}$ close to the tip of the blade. The flow rate has no influence on the tangential velocity; this result is not given in this study, but it confirms the one given by Wang et al. [6]. The condition of no slip at the wall is not to be respected in the case of passage of the blade close to the stator characterized by a non null velocity. It is highly probable that no-slip condition is verified but there is a high velocity gradient near to the wall.

The presence of the blades completely changes the velocity distribution. The flow in a SSHE is very complex, and highly depends on operating conditions. The origin of the temperature heterogeneities observed in these apparatuses strongly depends on the axial dispersion and on the weakness of radial mixture. Improvements for these devices are necessary to allow a good mixing process, and therefore the heat treatment of the product. To get further explanations on the achieved axial velocity profiles, other measurements should be undertaken to fully explain the observed phenomena at the inlet and outlet of the exchanger, together with an analysis of the velocity gradient based on these results. 
2

3

4

5

6

\section{References}

1. Alhamdan, A. and S.K. Sastry, Residence time distrubution of food and simulated particles in a holding tube. Journal of Food Engineering, 1997. 34: p. 271-292.

2. Alhamdan, A. and S.K. Sastry, Residence time distribution of food simulated particles in a model horizontal swept surface exchanger. Journal of Food Engineering, 1998. 21: p. $145-180$.

3. Russell, A.B., P.E. Cheney, and S.D. Wantling, Influence of freezing conditions on ice crystallisation in ice cream. Journal of Food Engineering, 1998. 39(2): p. 179-191.

4. Trommelen, A.M. and W.J. Beek, Flow phenomena in a scraped-surface heat exchanger ("Votator"-type). Chemical Engineering Science, 1971. 26(11): p. 19331942.

5. Wang, W., J.H. Walton, and K.L. McCarthy, Flow profiles of power law fluids in scraped surface heat exchenger geometry using MRI. Journal of Food Engineering, 1999. 22: p. 11-27.

6. Wang, W., J.H. Walton, and K.L. McCarthy, Mixing in scraped surface heat exchanger Geometry using MRI. Journal of Food process Engineering, 2000. 23(6): p. 403-418.

7. Stranzinger, M., K. Feigl, and E. Windhab, Non-Newtonian flow behaviour in narrow annular gap reactors. Chemical Engineering Science, 2001. 56(11): p. 3347-3363.

8. Stranzinger, M., et al., Effects of flow incidence and secondray mass flow rate on flow structuring contributions in scraped surafce heat exchangers. Journal of Food process Engineering, 2002. 25: p. 159-187.

9. Härröd, m., A literature survey of flow patterns, mixing, residence time distrubution, heat transfer and power requirements. Journal of Food process Engineering, 1986. 9(1-62).

10. Abichandani, H., S.C. Sharma, and D.R. Heldman, Hydrodynamics and heat transfer in liquid full scraped surface heat exchangers- A review. Journal of Food Process Engineering, 1987. 9: p. 121-141.

11. Dumont, E., et al., Wall shear rate in the Taylor-Couette-Poiseuille flow at low axial Reynolds number. International Journal of Heat and Mass Transfer, 2002. 45(3): p. 679-689.

12. Naimi, M., Etude des lois d'écoulement et de transfert de chaleur pour des fluides non-newtoniens en espace annulaire tournant. Approche réaliste de l'échangeur à surface raclée., in ENSEM-LEMTA. 1989: INP, Lorraine. 
1 13. Dumont, E., F. Fayolle, and J. Legrand, Flow regimes and wall shear rates determination within a scraped surface heat exchanger. Journal of Food Engineering, 2000 c. 45(4): p. 195-207.

14. De Goede, R. and E.J. De Jong, Heat transfer properties of a scraped-surface heat exchanger in the turbulent flow regime. Chemical Engineering Science, 1993. 48(8): p. 1393-1404.

15. Lakhdar, M.B., Lakhdar, M. B., J. Moureh., D. Flick., W. Gautherin., A. Lallemand, Simulation numérique des écoulements et des transferts dans un échangeur de chaleur à surface raclée. Récents progrès en génie des procédés, 1997. 11(53): p. 139-144.

16. Baccar, M. and M.S. Abid, Numerical analysis of three-dimensional flow and thermal behaviour in a scraped-surface heat exchanger. Revue Générale de Thermique, 1997. 36(10): p. 782-790.

17. Baccar, M. and M.S. Abid, Simulation numérique des comportements hydrodynamiques et thermiques des échangeurs racleurs opérant en regime turbulent: Numerical simulations of hydrodynamic and thermal behaviours in a scraped surface heat exchanger operating in turbulent regime. International Journal of Thermal Sciences, 1999. 38(7): p. 634-644.

18. Yataghene, M., F. Francine., J. Legrand., CFD analysis of the flow pattern and local shear rate in a scraped surface heat exchanger. Chemical Engineering and Processing, 2007. in Press.

19. Adrian, R.J., Bibliography of particle velocimetry using imaging methods: 1917-1995. Technical Report 817, University of Illinois, 1996.

20. Adrian, R.J., Particle imaging techniques for experimental fluid mechanics. Annual Review of Fluid Mechanics, 1991. 23: p. 261-305.

21. Raffel, M., C. Willert, and J. Kompenhans, Particle Image Velocimetry: a Practical Guide. Heidelberg, Springer, 1998.

22. Cenedese, A., G. Doglia, and G.P. Romano, LDV and PIV velocity measurements in free jets. Experimental Thermal and Fluid Science, 1994. 9: p. 125-134.

23. Nakagawa, S. and T.J. Hanratty, Image velocimetry measurements of flow over a wavy wall. Physics of Fluids, 2001. 13(11): p. 3504 - 3507.

24. Shineeb, A., J.D. Bugg, and R. Balachandar, PIV measurements in a confined jet,. Paper No. FEDSM2002-31160, ASME, Fluids Engineering Division Summer Meeting, Montreal, Canada, 2002.

25. Nezu, I. and K. Onitsuka, Turbulent structures in partly vegetated open-channel flows with LDV and PIV measurements. Journal of Hydraulic Research, IAHR, 2001. 39(6): p. 629-642. 
26. Nezu, I. and T. Nakayama, Space-time correlation structures of horizontal coherent vortices in compound channel flows by using particle-tracking velocimetry. Journal of Hydraulic Research, IAHR, 1997. 35(5): p. 191- 208.

27. Adrian, R.J., Dynamic ranges of velocity and spatial resolution of particle image velocimetry. Measurement Science and Technology, 1997. 8: p. 1393-1398.

28. Wen, J., Yanzhong Li., Aimin Zhou., Ke Zhang., An experimental and numerical investigation of flow patterns in the entrance of plate fin heat exchanger. International journal of heat and mass transfer, 2006: p. 1-11.

29. Wernet, M.P., Application of DPIV to study both steady state and transient turbomachinery flows. Optics \& Laser Technology, 2000. 32: p. 497-525.

30. Dumont, E., F. Fayolle, and J. Legrand, Electrodiffusional Wall Shear Rate Analysis in Scraped Surface Heat Exchanger. AIChE Journal, 2000 b. 46(6): p. 1138-1148.

31. Nouar, C., B. Benaouda, and C. Desaubry, Laminar mixed convection in a horizontal annular duct. Case of thermodependent non-Newtonian fluid. European Journal of Mechanics - B/Fluids, 2000. 19: p. 423-452.

32. Wereley, S.T. and R.M. Lueptow, Velocity field for Taylor-Couette flow with an axial flow. Physics of Fluids, 1999. 11(12): p. 3637-3649.

33. Maingonnat, J.F. and G. Corrieu, Etude des performances thermiques d'un échangeur de chaleur à surface raclée. 2ème partie. Influence de la dispersion axial de chaleur sur les performances thermique. Entropie, 1983 b(111): p. 37-48.

34. Maingonnat, J.F. and G. Corrieu, Etude des performances thermiques d'un échangeur de chaleur à surface raclée. lère partie. Revue des principaux modèles décrivant le transfert de chaleur et la consommation de de puissance. Entropie, 1983 a. 111: p. 2936.

35. Dumont, E., D. Della Valle, and F. Fayolle, Influence of flow regimes on temperature heterogeneties within a scraped surface heat exchanger. Journal of Food process Engineering, 2000 a. 23: p. 207-220.

36. Härröd, M., Methods to distinguish between laminar and vortical flow in scraped surface heat exchanger. Journal of Food process Engineering, 1990 c. 13: p. 39-57.

37. Wang, W., J.H. Walton, and K.L. McCarthy, Flow profiles of power law fluids in scraped surface heat exchanger geometry using MRI. Journal of Food process Engineering, 1999. 22(1): p. 11-27.

38. Wang, 1. and D.-W. Sun, Recent developments in numerical modelling heating and cooling processes in the food industry-a review. Food Science and Technology, 2003. 14: p. 408-423. 
$139 . \quad$ Stranzinger, M., Numerical and experimental investigations of Newtonian and non2 Newtonian flow in annular gaps with scraper blades, Dissertation. Technische Wissenschaften 3 ETH Zürich, Nr. 13369, 2000.

4

5 


\section{$\underline{\text { Tables list }}$}

2

3 Table 1 Apparatus dimensions

4

\begin{tabular}{ll}
\hline & $\begin{array}{l}\text { Dimensions of } \\
\text { used scale down } \\
\text { model SSHE }\end{array}$ \\
\hline Stator radius $\mathrm{R}_{\mathrm{s}}$ & $0.0325 \mathrm{~m}$ \\
Stator length $(\mathrm{L})$ & $0.40 \mathrm{~m}$ \\
Rotor radius $\left(\mathrm{R}_{\mathrm{r}}\right)$ & $0.020 \mathrm{~m}$ \\
Rotor plate radius $\left(\mathrm{R}_{\mathrm{rp}}\right)$ & $0.0168 \mathrm{~m}$ \\
Total length with blows $(\mathrm{Lt})$ & $0.530 \mathrm{~m}$ \\
Area of cross-section $(\mathrm{S})$ & $2.10^{-3} \mathrm{~m}^{2}$ \\
Total volume of SSHE $(\mathrm{Vt})$ & $10^{-3} \mathrm{~m}^{3}$ \\
Bowl volume $\left(\mathrm{V}_{\mathrm{b}}\right)$ & $1.2510^{-4} \mathrm{~m}^{3}$ \\
Ratio $\left(\mathrm{V}_{\mathrm{t}} / \mathrm{V}_{\mathrm{b}}\right)$ & 4 \\
\end{tabular}

6

7

8

9 Table 2: Operating Conditions

\begin{tabular}{lllllll}
\hline & \multicolumn{2}{l}{ Flow rate $(1 / \mathrm{h})$} & & \multicolumn{3}{l}{ Rotating velocity (rev/s) } \\
\hline & 0 & 50 & 150 & 1 & 3 & 5 \\
\hline & $\operatorname{Re}_{a x g}=8^{1-n}\left(\frac{4 n}{3 n+1}\right) \frac{\rho U_{d}^{2-n} d_{h}^{n * *}}{k}$ & $T a_{g}=\sqrt{\frac{R_{s}-R_{r}}{R_{r}}} \frac{\rho d_{h}^{n}}{2^{n}} \frac{\left(\Omega R_{r}\right)^{2-n}}{k}$ \\
\hline Pure Glycerine & 0 & 0,16 & 0.49 & 1.19 & 3.58 & 5.97 \\
Glycerine 15\% & 0 & 1.87 & 5.60 & 10.10 & 30.30 & 50.50 \\
CMC 1\% & 0 & 0.024 & 0.13 & 0.66 & 4.07 & 9.50 \\
CMC 0.5 \% & 0 & 0.32 & 1.52 & 5.37 & 25.86 & 53.69 \\
\hline
\end{tabular}

10

$* 15 \%$ volume of water

$11 * *$ For Newtonian fluid $\mathrm{n}=1$

12

13

14

15

16

17 
1

2 Table 3 : Fluids Properties

\begin{tabular}{|c|c|c|c|}
\hline \multirow[t]{2}{*}{ Fluids } & \multicolumn{2}{|c|}{ Viscosity at $18^{\circ} \mathrm{C}$} & \multirow{2}{*}{$\begin{array}{l}\text { Density } \\
\left(\mathrm{kg} / \mathrm{m}^{3}\right)\end{array}$} \\
\hline & (Pa.s) & & \\
\hline Pure glycerin & 1,31 & & 1260 \\
\hline \multirow[t]{2}{*}{ Glycerin $15 \%$ of water } & 0.11 & & 1220 \\
\hline & $\left(\mathrm{Pa} / \mathrm{s}^{\mathrm{n}}\right)$ & $\mathrm{n}[-]$ & \\
\hline CMC $1 \%$ & 12.83 & 0.34 & 1048 \\
\hline CMC $0.5 \%$ & 0,65 & 0.57 & 1043 \\
\hline
\end{tabular}

3 


\section{Figures list:}

2

3

4

5

6

7

8

9

10

11

12

13

14

15

16

17

18

19

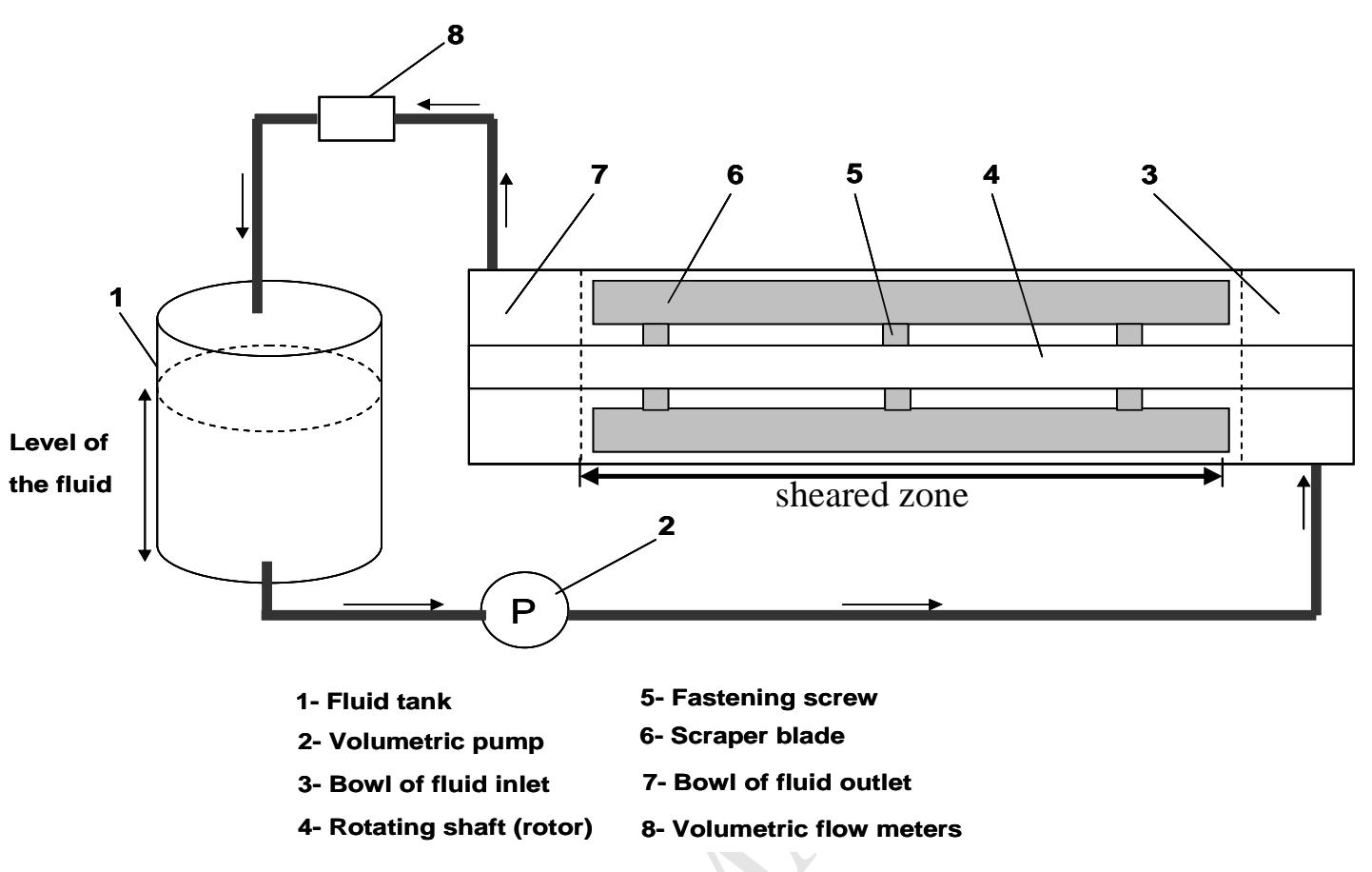

20

21 Fig.1. Schematic representation of experimental setup. 
1

2

3

4

5

6

7

8

9

10

11

12

13

14

15

16

17

18

19

20

21

22

23

24

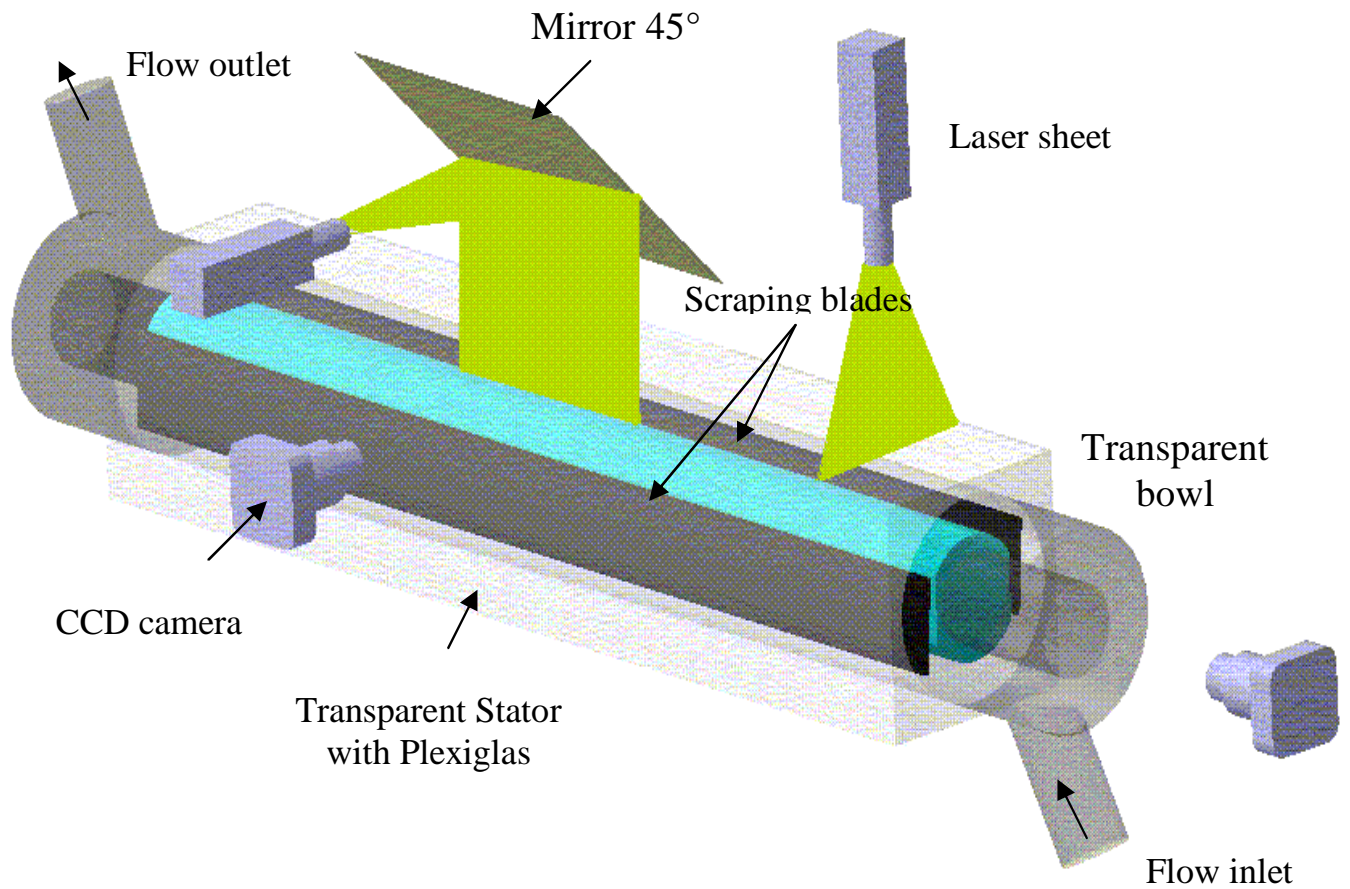

Flow inlet

Fig.2. Schematic representation of the camera and laser positions. 

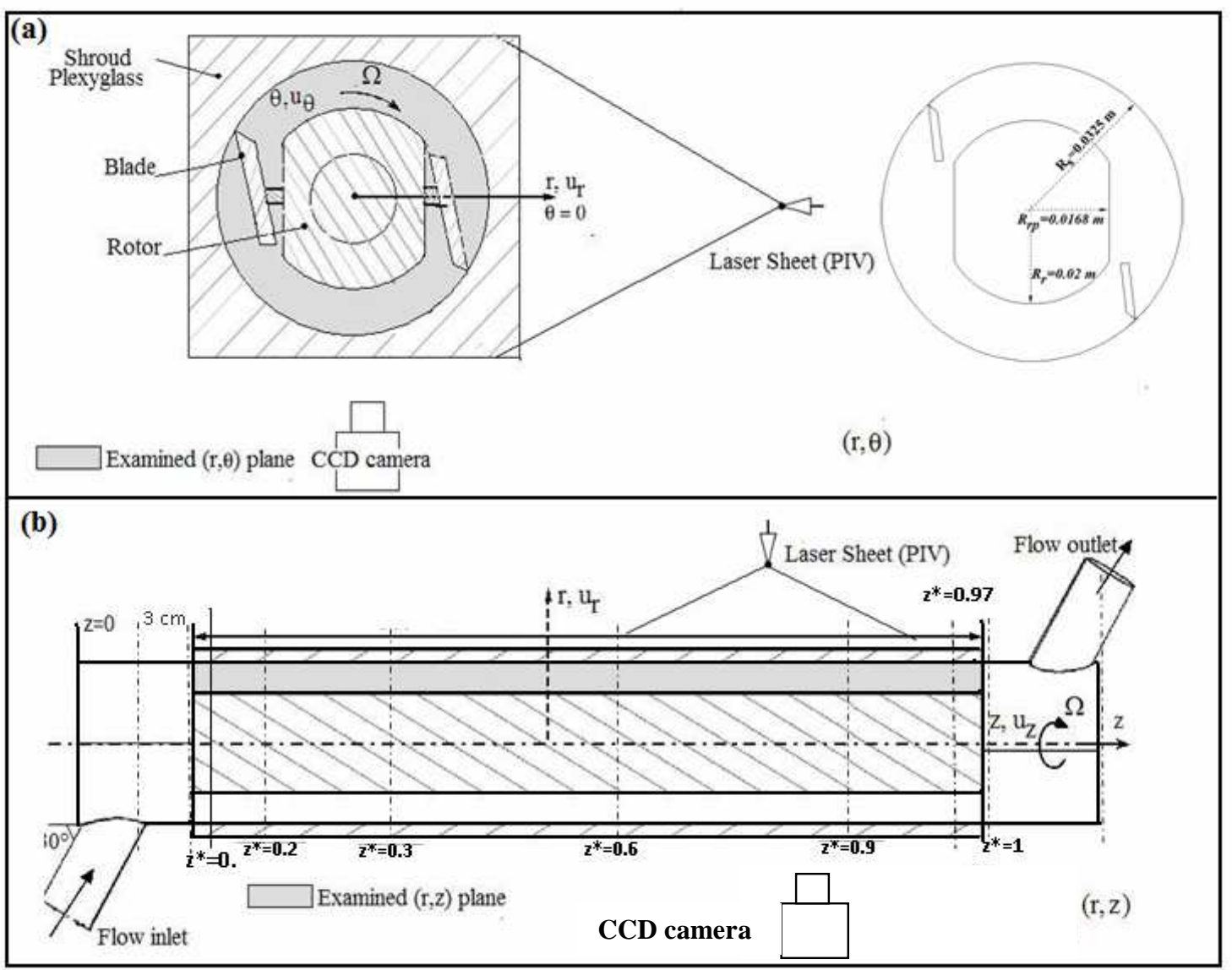

3

4

5

6 Fig.3. Test sections used in the PIV experiments: a) radial and tangential velocity 7 components, b) axial and radial velocity components. 


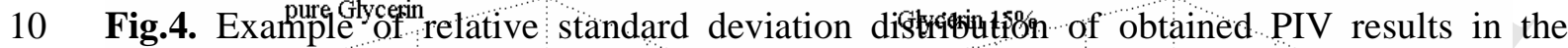
12 middle planie $\mathrm{r}-\mathrm{Z}$ and in case of four considered fluids $\left(\mathrm{N}=3 \mathrm{rev} / \mathrm{s}, \mathrm{Q}_{\mathrm{v}}=1.3810^{-5} \mathrm{~m}^{3} / \mathrm{s}, \theta=90^{\circ}\right)$.

14

16
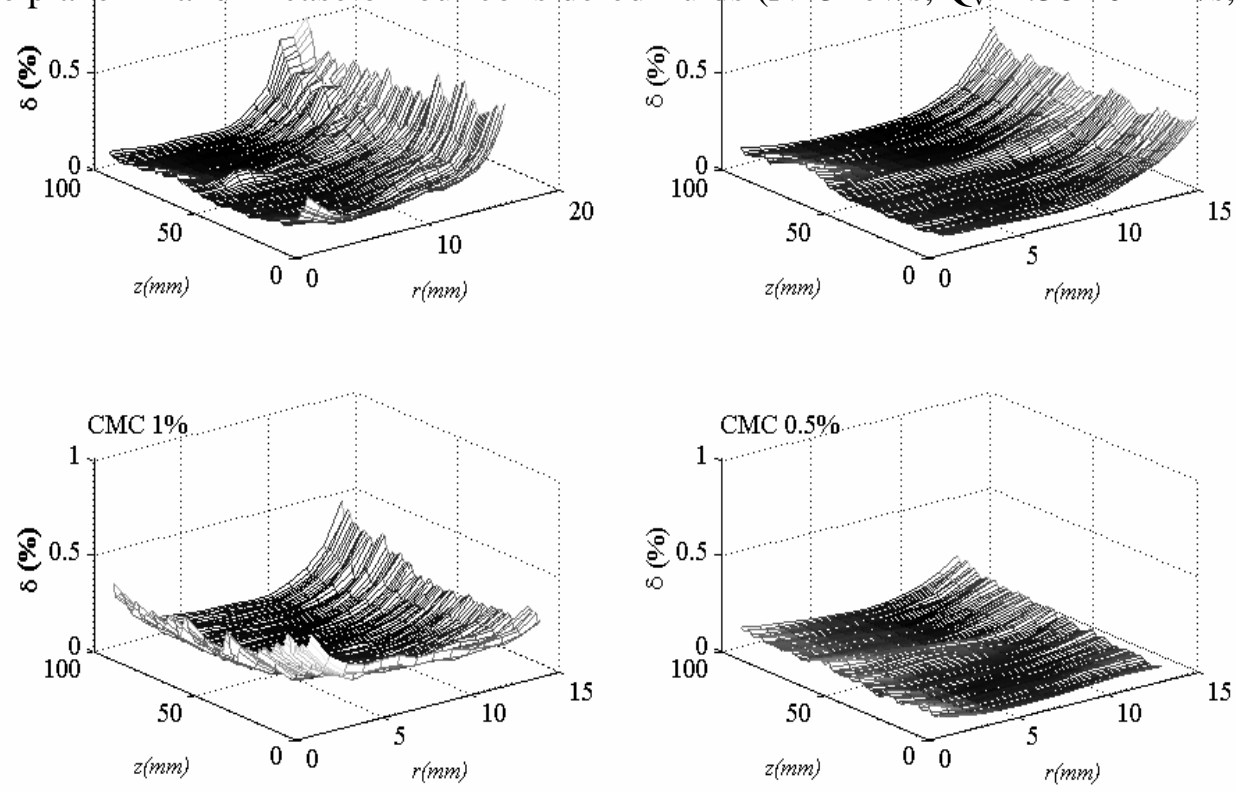

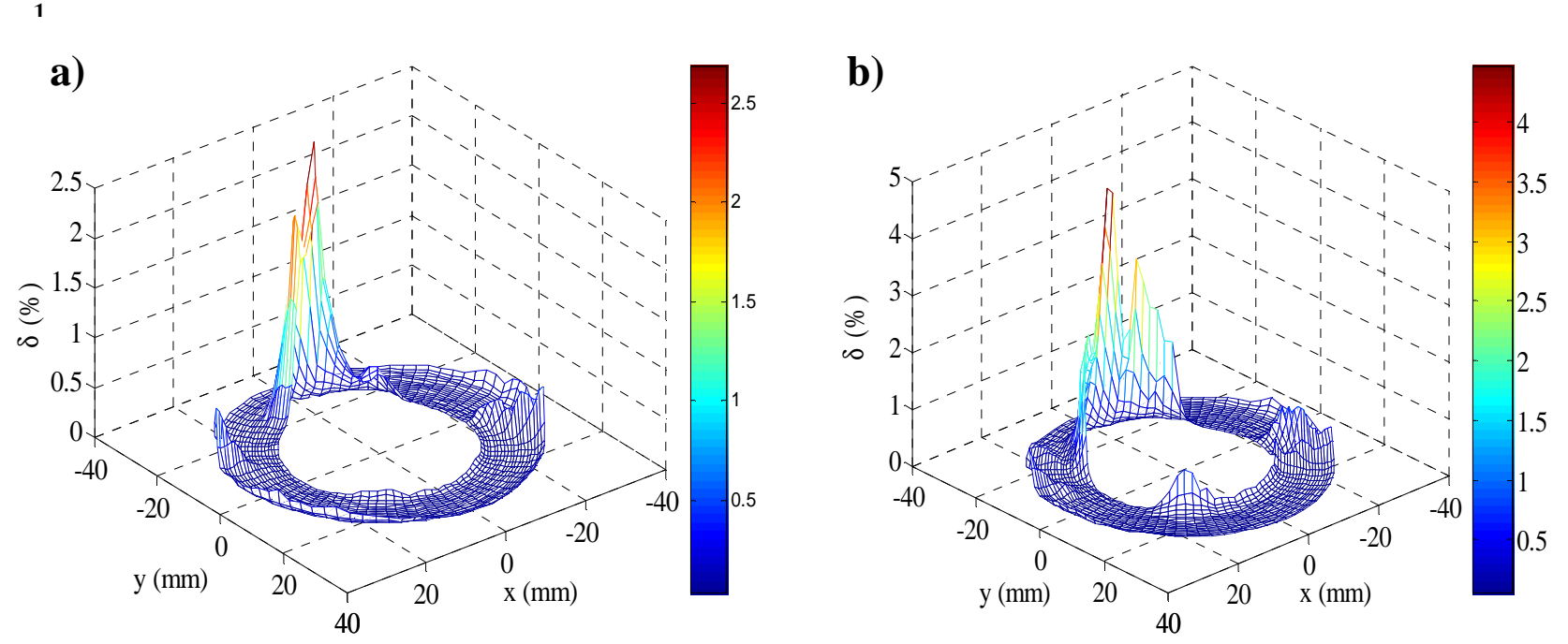

15

16

17

18 Fig.5. Example of relative standard deviation distribution of obtained PIV results 19 corresponding to $\mathrm{r}-\theta$ plane and in the case of a) pure glycerin, b) $1 \% \mathrm{CMC}$ solution ( $\mathrm{N}=3$ $20 \mathrm{rev} / \mathrm{s}, Q_{v}=1.3810^{-5} \mathrm{~m}^{3} / \mathrm{s}, \mathrm{z}^{*}=0.2$ ).

21

22

23

24

25

26

27

28

29

30

31

32

33

34

35

36 
1
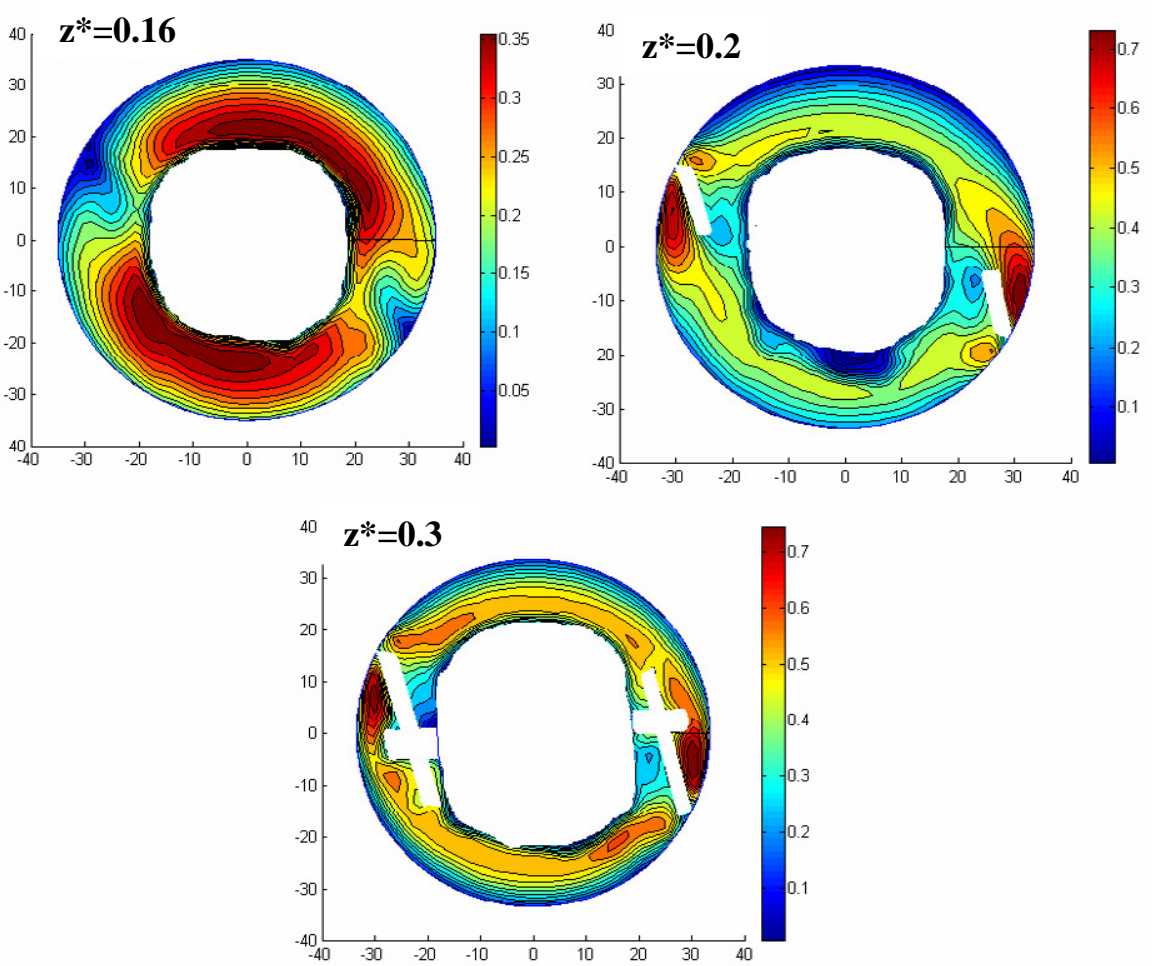

3

Fig.6. Magnitude of tangential velocity contour of $\left(\mathrm{v}_{\theta}{ }^{2}+\mathrm{v}_{\mathrm{r}}\right)^{2}{ }^{0.5}$ at $\mathrm{z}^{*}$-locations of $0.16,0.2$ and 50.3 respectively, pure glycerin, $\mathrm{N}=5 \mathrm{rev} / \mathrm{s}, \mathrm{Q}_{\mathrm{v}}=1.3810^{-5} \mathrm{~m}^{3} / \mathrm{s}$. 
2

3

4

5

6

7

8

9

10

11

12

13

14

15

16

17

18

19

20

21

22

23

24

25

26
Blades
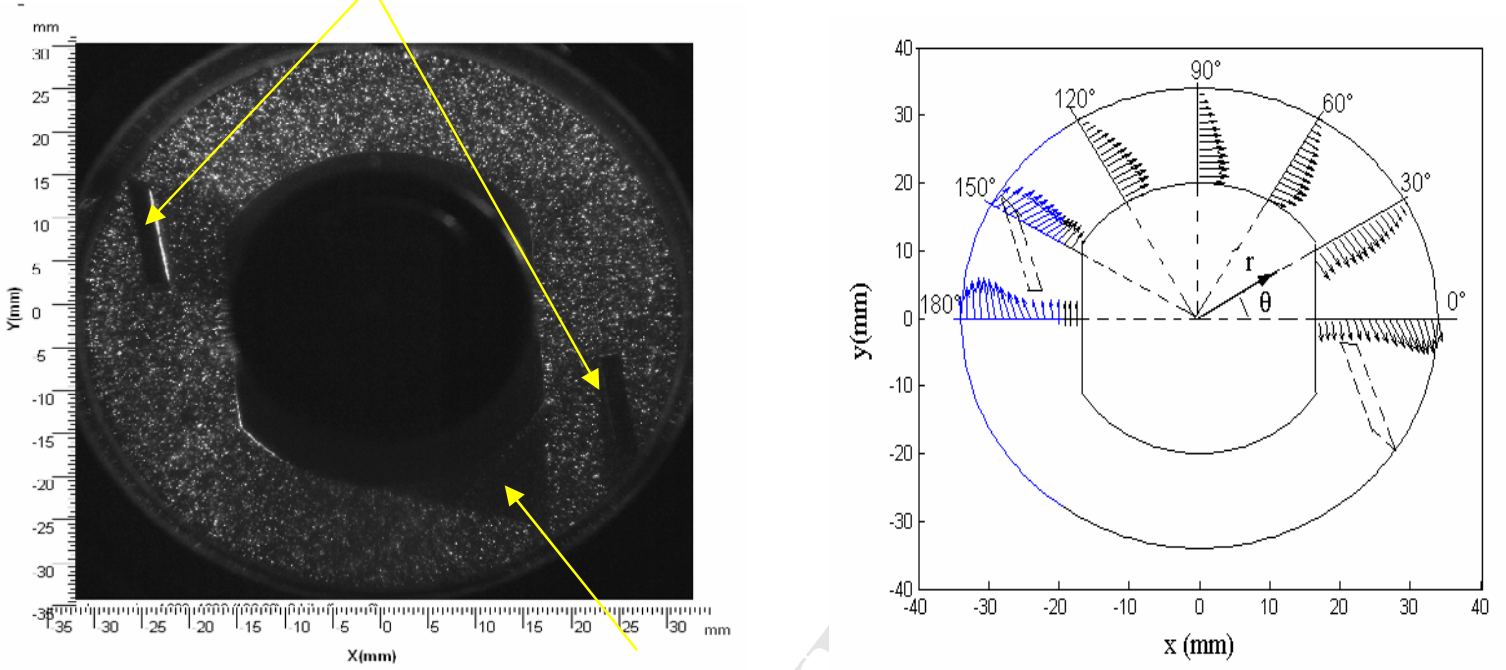

Shadowed

zone

Fig.7. Seeded flow example for $z^{*}=0.2$ in the presence of the blades (left), tangential velocity plots for different angular positions (right). 
a)
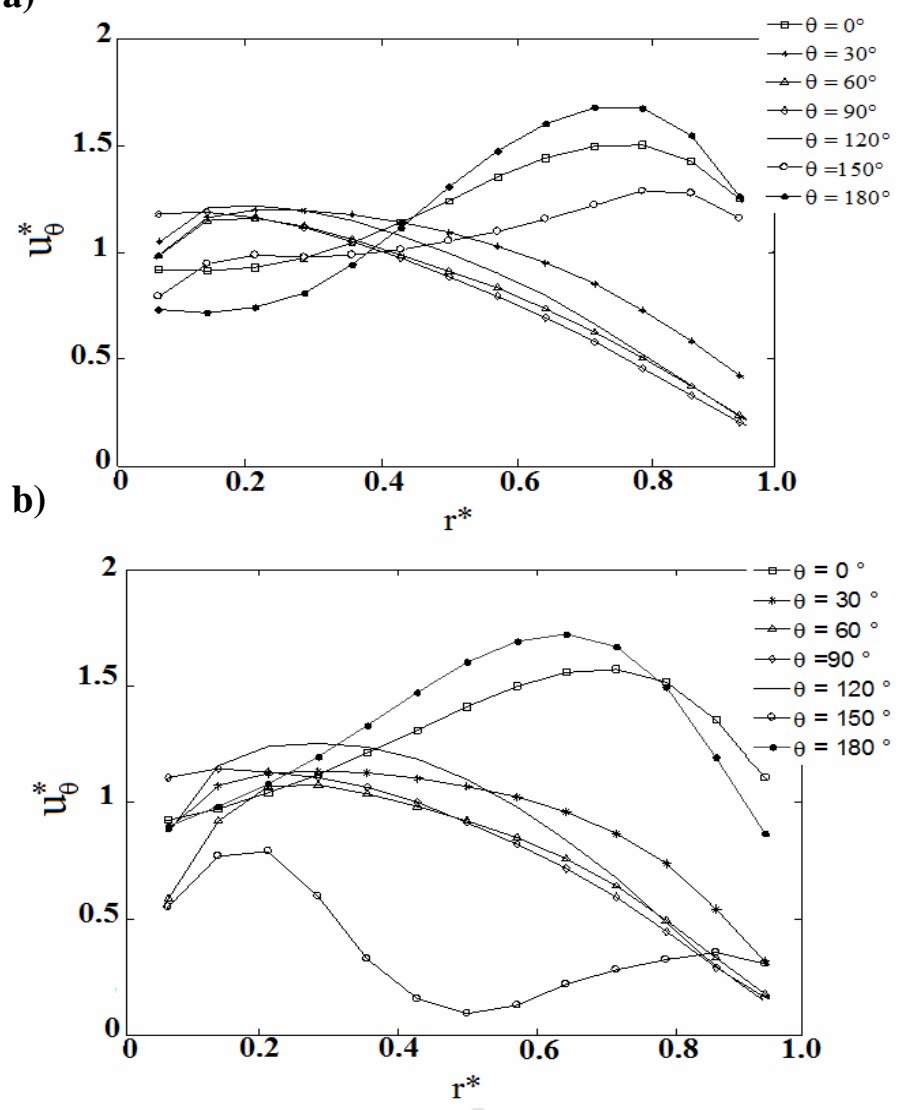

3

Fig.8. Normalized tangential velocity plots in different angular positions for $N=3 \mathrm{rev} / \mathrm{s}$, $Q_{v}=1.3810^{-5} \mathrm{~m}^{3} / \mathrm{s}, a$ ) pure glycerin, $b$ ) $1 \% \mathrm{CMC}$ solution. 
a) Pure glycerin

Entrance plane

2

3

4

5

6

7

8

9

10

11

12

13

14

15

16

17

18

19

20

21

22

23

24

25

26

27

28

29

30

31

32

33

34

35

36

37

38

39

40

41

42

43

44

45

46

47

48

49
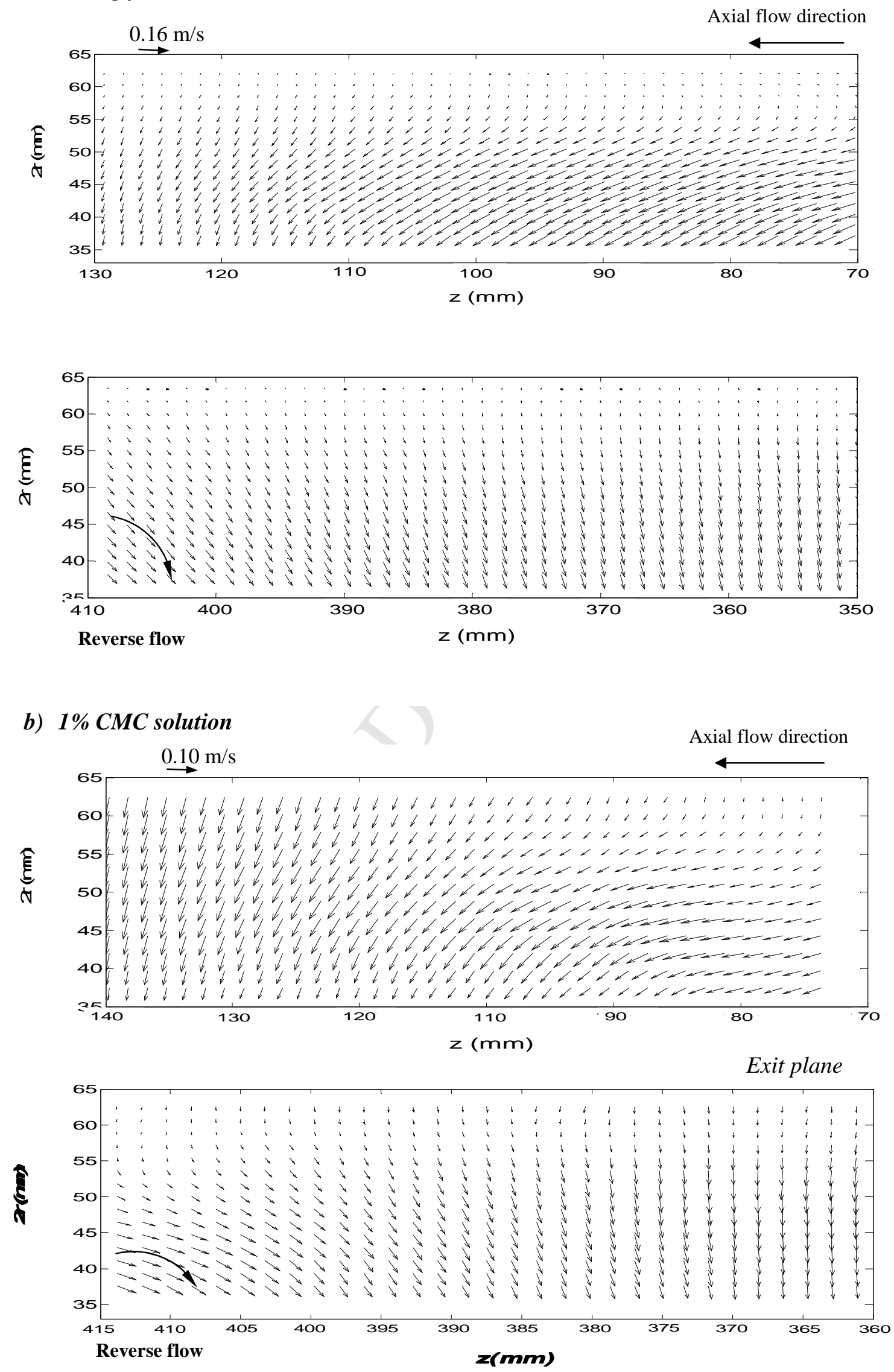
1 Fig.9. Mean velocity vectors plots in $r-z$ planes in the case of $a$ ) pure glycerin and $b) 1 \%$ 2 CMC solution, $N=5 \mathrm{rev} / \mathrm{s}$ and $Q_{v}=1.3810^{-5} \mathrm{~m}^{3} / \mathrm{s}$, entrance plane and exit plane, $\theta=90^{\circ}$. 
a) Flow direction

1
2

3

4

5

6

7

8

9

10

11

12

13

14

15

16

17

18

19

20

21

22

23

24

25

26

27

28

29

30

31

32

33

34

35

36

37

38

39 b) Flow direction

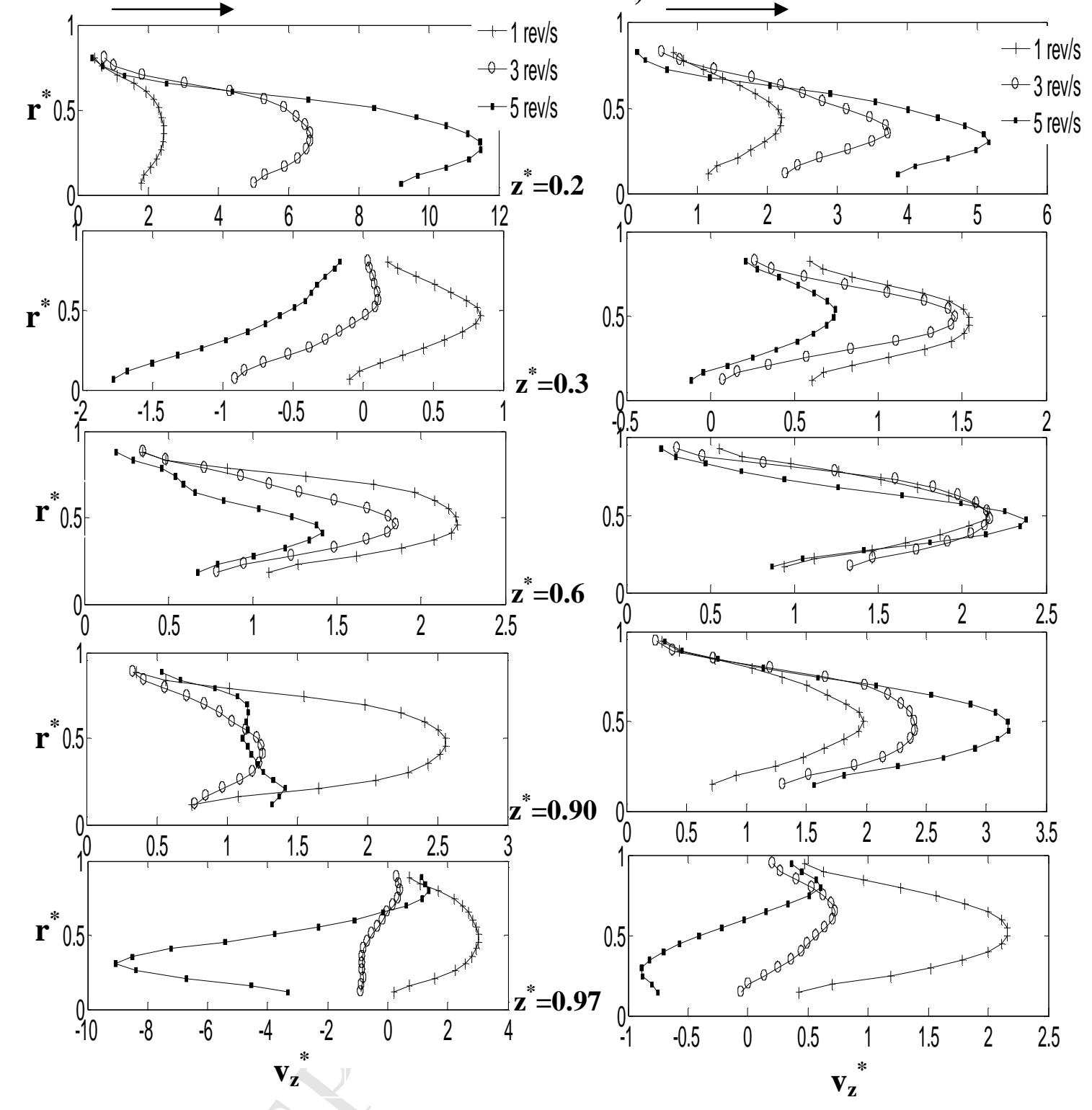

Fig.10. Normalized axial velocity profiles for pure glycerin at different $z^{*}$ positions and rotating velocity: a) $\left.Q_{v}=1.3810^{-5} \mathrm{~m}^{3} / \mathrm{s}, b\right) Q_{v}=4.210^{-5} \mathrm{~m}^{3} / \mathrm{s}, \theta=90^{\circ}$. 
a) $\underset{\text { Flow direction }}{\longrightarrow}$

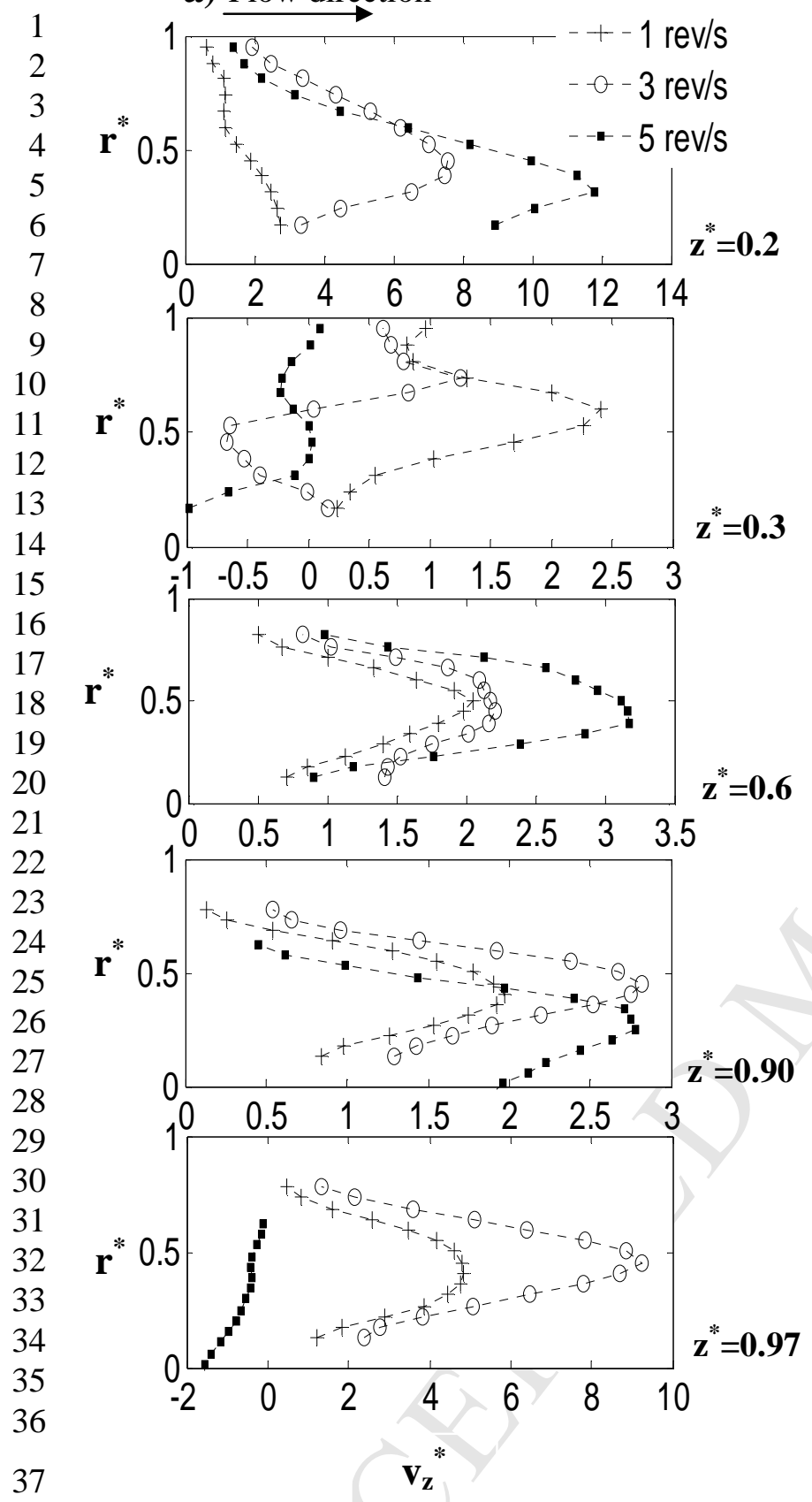

b) Flow direction

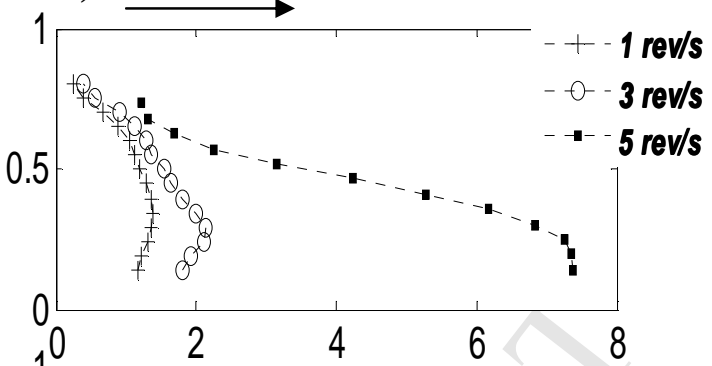

0.5
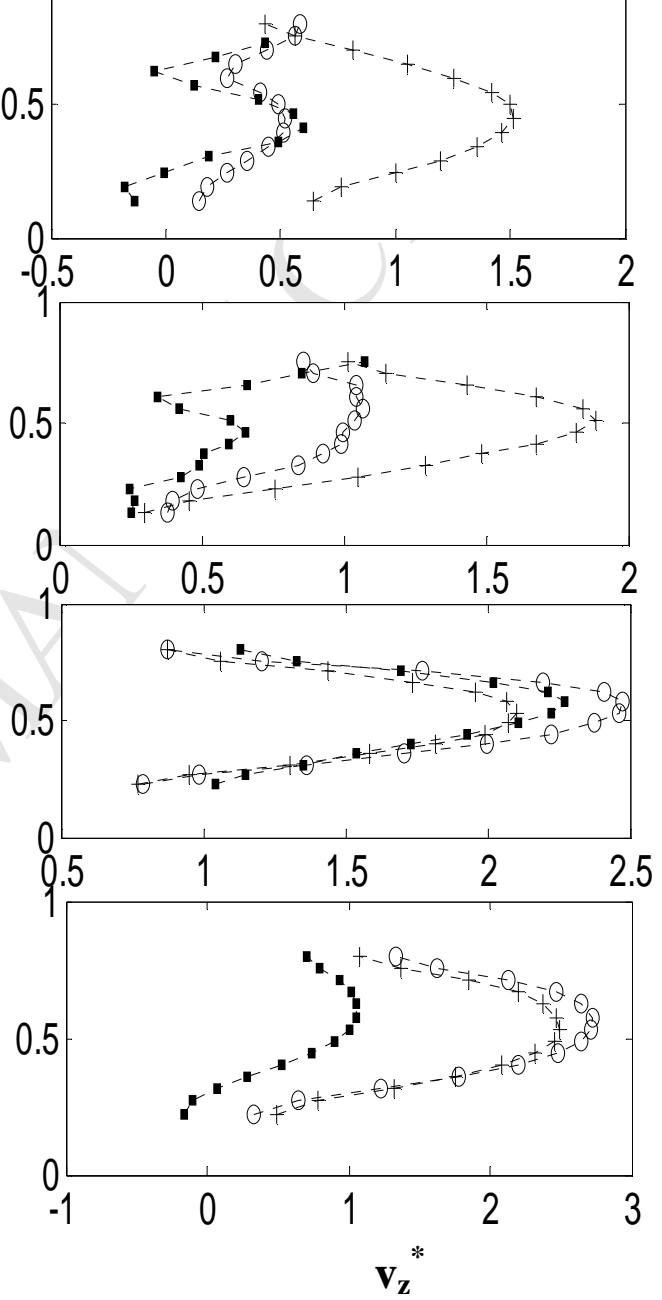

Fig.11. Normalized axial velocity profiles for $1 \% C M C$ solution at different $z^{*}$-locations of and rotating velocity: a) $Q_{v}=1.3810^{-5} \mathrm{~m}^{3} / \mathrm{s}$, b) $Q_{v}=4.210^{-5} \mathrm{~m}^{3} / \mathrm{s}, \theta=90^{\circ}$. 


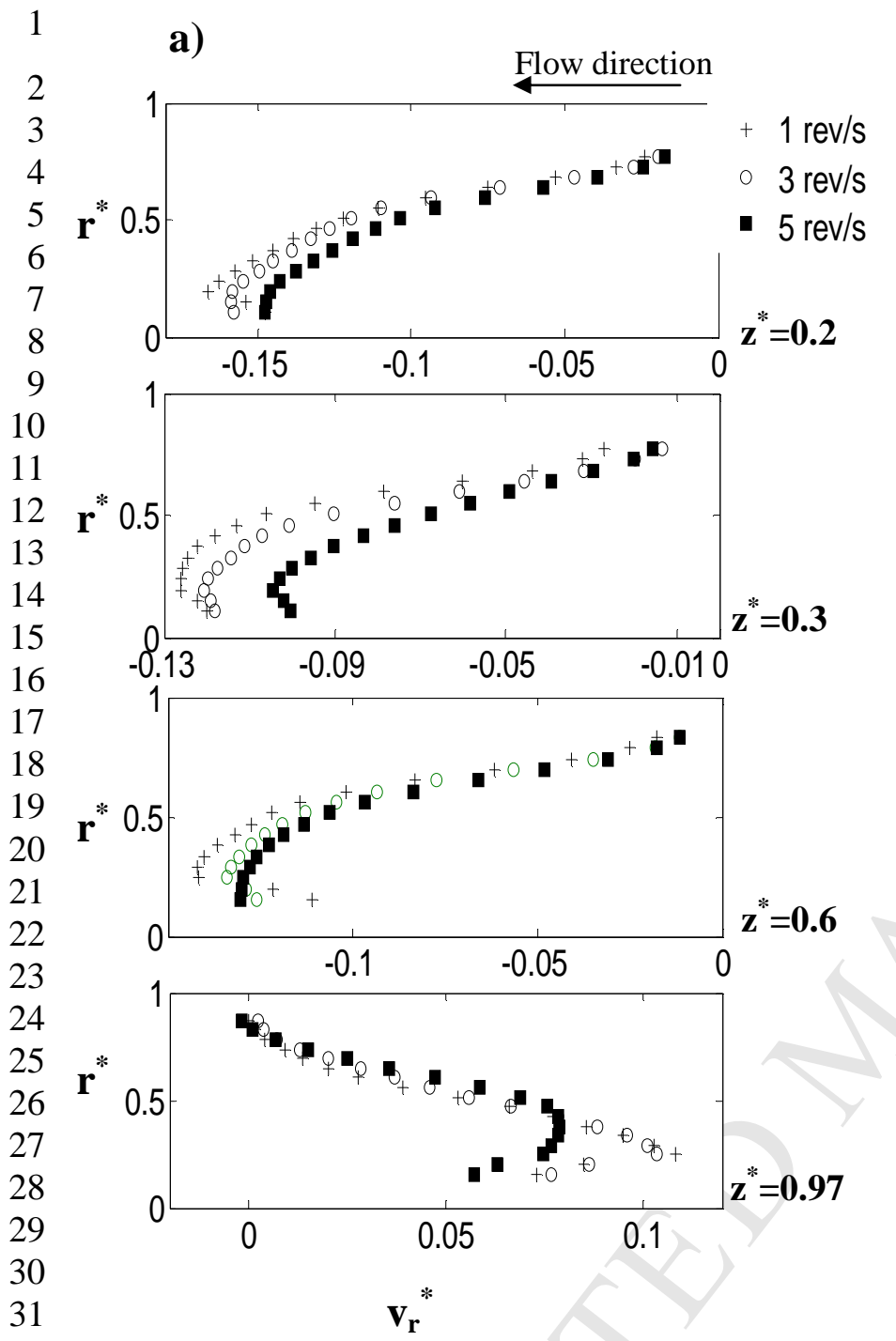

b)

Flow direction
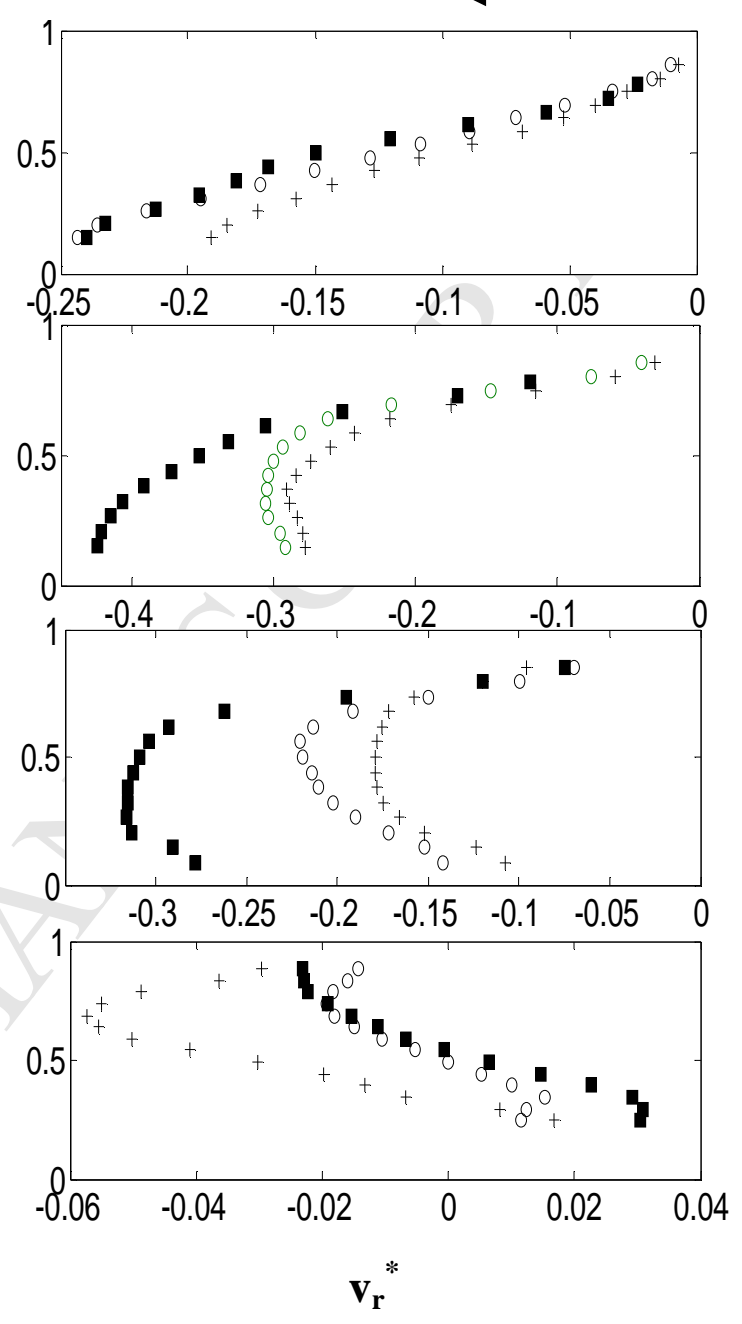

Fig.12. Normalized radial velocity plots across $(r, z)$ planes for $N=1,3$ and $5 \mathrm{rev} / \mathrm{s}$, $34 Q_{v}=4.210^{-5} \mathrm{~m}^{3} / \mathrm{s}:$ a) pure glycerine, $b$ ) $1 \% \mathrm{CMC}$ solution, $\theta=90^{\circ}$. 
a)

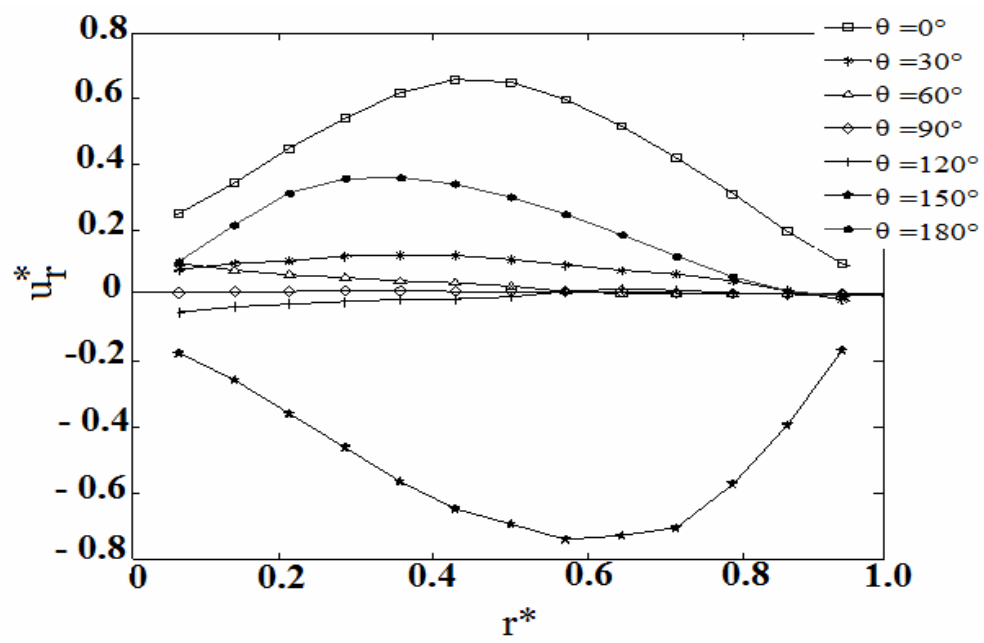

b)

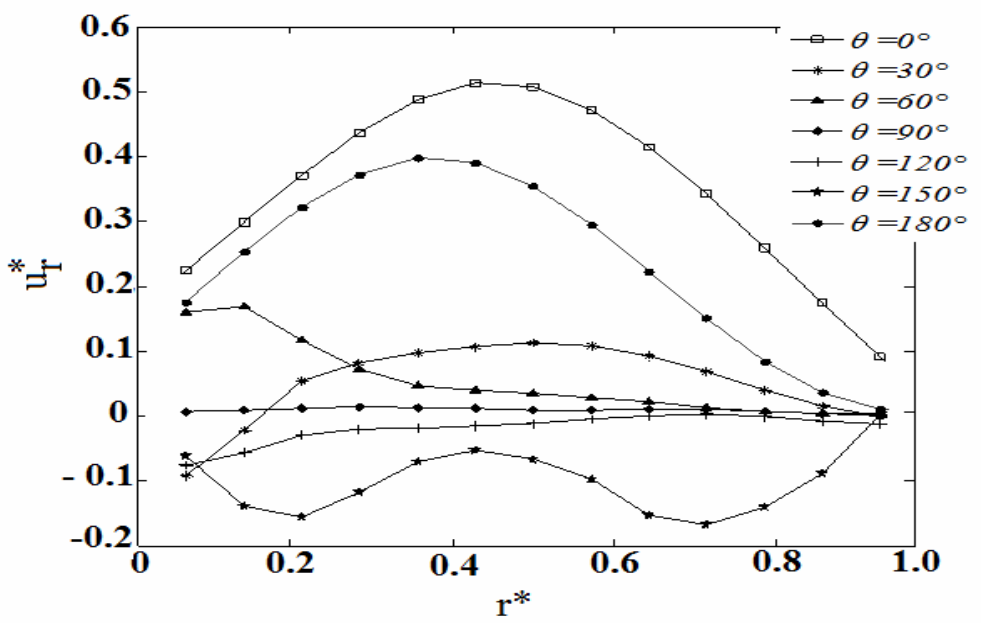

2

4

5

6

7 8

Fig.13. Normalized radial velocity plots in different $\theta$-angular positions for $N=3 \mathrm{rev} / \mathrm{s}$, $Q_{v}=1.3810^{-5} \mathrm{~m}^{3} / \mathrm{s}:$ a) pure glycerine, $b$ ) $1 \% \mathrm{CMC}$ solution. 


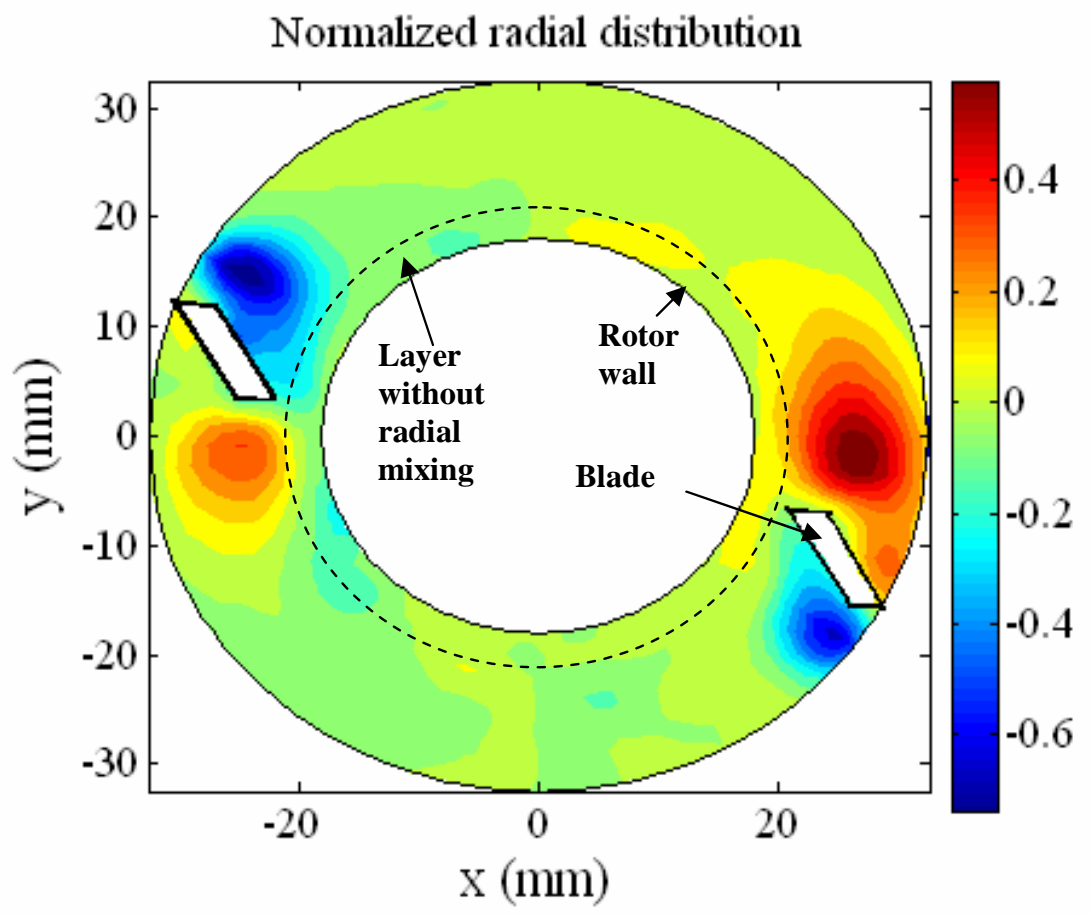

Fig.14. Normalized radial velocity distribution in $r-\theta$ plane corresponding to $z^{*}=0.6$ and for the operating conditions of pure glycerine $\left(N=3 \mathrm{rev} / \mathrm{s}\right.$ and $\left.Q_{v}=1.3810^{-5} \mathrm{~m}^{3} / \mathrm{s}\right)$. 


\section{$\underline{\text { Highlights }}$}

1. The PIV was used to add a new knowledge on the flow structure within a SSHE

2. Synchronization of laser and rotating blades was made allowed statistical analysis

3. Axial heterogeneities at the entrance and exit of SSHE were observed

4. Radial velocity was showed a good mixing around the blades

5. Tangential velocity have shown a maximum localized near the tip of the blade 